\title{
Urdiduras Continentais no debate acerca do Mission Style. Notas sobre o Pan-Americanismo na Arquitetura Neocolonial
}

\author{
Fernando Atique ${ }^{1}$
}

\begin{abstract}
Resumo: A arquitetura neocolonial foi produzida com ênfase, no Brasil, entre os anos de 1910 e 1950. Embora defendida por arquitetos e intelectuais brasileiros como "produto legítimo" de uma cultura brasileira, podemos notar, sob outro ponto de vista, que ela revela o contato do Brasil com todo o continente americano por meio das similaridades de suas formas e de seu discurso. De fato, durante a década de 1920 o suposto caráter homogêneo e nacional do neocolonial arrefeceu através da introdução de conceitos espaciais, ornamentos e modelos arquitetônicos de matriz hispano-estadunidense conhecidos como mission style. A combinação do mission style com o neocolonial brasileiro produziu uma arquitetura nova, com um caráter pan-americano mais explícito, agregando valores e imagens comuns a todas as Américas, mas sobretudo, dos Estados Unidos em seu bojo. O objetivo principal deste artigo é, assim, discutir as origens desse "neocolonial pan-americano". Para tanto, analisam-se arquitetos, livros, manuais e universidades que, do Brasil, olharam para toda a América tentando encontrar respostas políticas e estéticas para esta questão. Em especial, o trabalho destaca a presença dos Estados Unidos nessa pan-americanização da arquitetura, pois foi o país que enviou as fontes mais influentes para sua feitura.
\end{abstract}

Palavras chave: Arquitetura neocolonial; mission style; pan-americanismo.

\begin{abstract}
The "neocolonial architecture" was produced, in Brazil, with preponderance between the 1910's and 1950's. Despite of this visible existence in Brazilian cities, this kind of architecture was as taboo in Brazilian architectural historiography. The existence of forms and ornaments used in the Brazilian colonial period and recuperated by the neocolonial architecture revealed the Brazilian contact with the whole American continent. In fact, during the 1920's the supposed national and homogeneous character of the neocolonial felt down by the introduction of spatial concepts, ornaments and architectural models from the American-Spanish colonial architectural, best know as mission style, producing the rise of a pan-american architecture. The main purpose of this article is to discuss the sources of this "panamerican neocolonial." For it, the paper reveals the most important architects, books, manuals and Universities, in Brazil, that looked for the whole America trying to find aesthetical and political answers for this architecture. In special, the paper points the importance of the United States, the country that sent the most influent sources for this architecture.
\end{abstract}

Key words: Neocolonial architecture; mission style; pan-americanism.

\footnotetext{
${ }^{1}$ Arquiteto e urbanista, mestre e doutor em História da Arquitetura e do Urbanismo. Professor Adjunto do Departamento de História da Universidade Federal de São Paulo, na Área de Espaço e Patrimônio Edificado. Desenvolve pesquisas sobre profissionais e referências espaciais americanas no Brasil. Endereço para correspondência: UNIFESP - EFLCH. Estrada do Caminho Velho, 333, Jd. Nova Cidade, Guarulhos / SP. Página: http://humanas.unifesp.br E-mail: fernando.atique@unifesp.br.
} 


\section{Um Nacional, Internacional? A Arquitetura Neocolonial e suas Fontes Estrangeiras}

A palavra neocolonial, no campo da Arquitetura e do Urbanismo, é usada para se referir ao movimento de produção arquitetônica cujas matrizes estavam, supostamente, na antiga condição colonial das diversas repúblicas americanas, consideradas como detentoras da "essência" dos países do continente americano. A expressão, embora contemporânea dos mentores e artífices dessa forma de arquitetura, desagradava-lhes profundamente. Este desagravo era uma maneira político-ideológica de combater a ideia de que a arquitetura destinada a corporificar a identidade nacional era vinculada à seara de estilos praticados desde as últimas décadas do século XIX, dentro do escopo daquilo que se chamou, no campo artístico, de ecletismo. Este ecletismo, associado por parcela da intelectualidade artística das décadas de 1920 e 1930 a uma consequência pesarosa de desnacionalização da arte brasileira, foi, pelo menos textualmente, afastado da produção "neocolonial". Essa espécie de repúdio que, curiosamente anexou à palavra "ecletismo" uma pecha pejorativa, foi publicizado por diversos pensadores nacionais, em especial por José Marianno Carneiro da Cunha Filho². Em artigos publicados em jornais cariocas José Marianno Filho revelou um esquema de valorização da arquitetura inspirada nas edificações coloniais brasileiras que pressupunha uma crítica à produção de edifícios "de estilo" verificada nas cidades do Brasil. Em artigo intitulado "Right or Wrong, it is my house", de julho de 1931, publicado em $O$ Jornal, ele expôs que:

“(...) a preferencia do homem pela architectura pátria, tem, ao meu ver, independentemente de qualquer solicitação artística, um carater de insophismavel fundo emotivo. Quando o emigrante allemão que enriqueceu em São Paulo pensa em construir o seu 'home', elle pensa em allemão, porque as idéas da casa, da habitação, da família, lhe accordam

\footnotetext{
${ }^{2}$ Natural de Pernambuco, onde nasceu, em 1881, num engenho de nome Monjope, próximo a Recife, José Marianno Carneiro da Cunha Filho era filho de abastada família nordestina. Seu pai, como apontou Carlos Kessel, foi deputado do Império ligado à causa abolicionista. Sabe-se, também, que, desde cedo, José Marianno Filho residiu no Rio de Janeiro, junto com o pai e o irmão, o poeta Olegário Marianno. No Rio, José Marianno Filho formou-se em medicina, especializando-se em ginecologia, mas nunca chegou a clinicar (KESSEL, 2008, p.89-90). Ele foi casado com Violeta Siciliano, de família paulista. Desde cedo se envolveu com o círculo de poetas, escritores e artistas da antiga capital federal, o que lhe abriu as portas para as atividades que desempenharia vida afora, como a de crítico de artes e arquitetura. José Marianno Filho foi, também, diretor da Escola Nacional de Belas Artes, nos anos de 1926 e 1927; sóciofundador da Sociedade de Belas Artes e do Instituto Central de Arquitetos, ambos na cidade do Rio de Janeiro, em 1921, bem como membro-fundador de várias outras agremiações, como, do Rotary Club do Rio de Janeiro, em 1922.
} 
reminiscencias adormecidas profundamente no subconsciente. / Essa afirmação é tão verdadeira que através da physionomia das habitações domesticas, nós podemos com exactidão quasi infallivel prever a nacionalidade (e tambem a incultura) dos respectivos habitantes. (...) Portugueses e brasileiros se conduzem - no que diz respeito ao problema architectonico - de maneira verdadeiramente singular. / Ao invés de proceder como os italianos, inglezes ou allemães que preferem os estylos da própria nacionalidade, elles procuram insistentemente disfarçal-a ou mascaral-a" (CUNHA FILHO, O Jornal, Rio de Janeiro, jul, 1931, s.p.)

Assim, começa a ficar claro que a estrutura discursiva montada por José Marianno Filho para organizar a arquitetura que postulava era dual: mesmo sendo nova deveria apontar para a recuperação de elos com o passado.

Dessa forma, a duplicidade do neocolonial pressupunha a rejeição da máxima de que a arquitetura tradicional brasileira era o último fruto de uma "árvore eclética de estilos arquitetônicos" como diversos críticos do neocolonial, contemporâneos e sucedâneos apontaram. Para José Marianno Filho e seus seguidores, a arquitetura tradicional brasileira vinha recuperar uma dimensão que se perdeu quando, no século XIX, uma formação erudita de caráter francês foi introduzida no Brasil por conta da Academia Imperial de Belas Artes (CUNHA FILHO, O Jornal, 8 de jul, 1931, s.p.). José Marianno Filho defendia a tese de que a proliferação de estilos provenientes de outros países, se não destruiu, esmaeceu a plena demonstração da expressão da "raça brasileira" (CUNHA FILHO, 1942). Cria, ele, ainda, que a recondução das "expressões do povo" se processaria apenas por meio desse movimento que, de certa maneira, liderava já que o via como uma espécie de campanha recuperadora ${ }^{3}$ da forma e da sensibilidade estética do Brasil Colônia, nos "tempos modernos" (CUNHA FILHO, 1942).

Assim, em seus textos, há sempre uma longa e reincidente discussão semântica, que procura descolar o significado do movimento que daria origem à recuperação da arquitetura tradicional, mais erudita, daquele mais popularizado e de apropriação mais generalizada entre as camadas médias urbanas, chamado por Carlos Lemos de “neocolonial simplificado" (LEMOS, 1989). Neste sentido, no livro A Inquietação das Abelhas, publicado por Angyone Costa, em 1927, José Marianno Filho salientou que o emprego da palavra "estilo" mostrava-se como que destinado a sepultar o florescimento

\footnotetext{
${ }^{3}$ Não deve soar estranho, então, ver que, por diversas vezes, ele se auto-intitulou guerreiro numa cruzada, ou, ainda, "bandeirante de um ideal nobre" que a classe arquitetônica não compreendia. Em carta a Fernando de Azevedo, tergiversou: "Afinal de contas não me devo queixar. Ninguém mais poderá deter o surto da arquitetura brasileira” (A NOITE, 1927, p.1).
} 
das realizações arquitetônicas em curso pelo país afora. Frisava, ele, em contrapartida, que era por meio do emprego da expressão "arquitetura tradicional brasileira (imprópria e perversamente chamada estilo colonial)" que sua causa ganharia corpus (COSTA, 1927, p. 294). Vê-se, então, que a problemática do "neocolonial" não estava colocada apenas no patamar da construção, mas, sim, de um projeto metodológico de cultura por meio do espaço construído, o que, obviamente, passava pela definição semântica da arquitetura.

José Marianno insistia frequentemente nesse assunto da suposta "intromissão" de elementos e procedimentos arquitetônicos no seio da arquitetura "tradicional", imputando, assim, uma carga negativa do contato do Brasil com a Europa, sobretudo. Dizia ele que

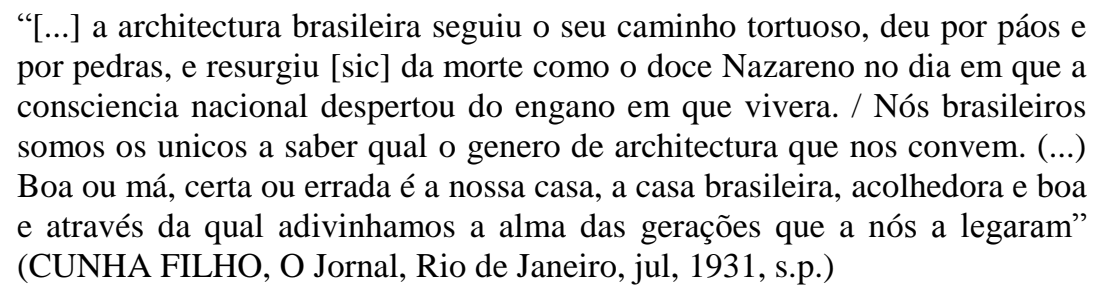

Mas quais eram as razões que estavam por trás dessa polêmica que comparece fortemente em discursos e na imprensa seriada brasileira das décadas de 1920 e $1930 ?^{4}$

Compreender a origem desta indagação talvez suplante a premência da própria resposta, uma vez que o processo histórico que dá origem à discussão acerca da arquitetura neocolonial no Brasil precisa ser analisado de um ponto de vista panamericano antes de ser taxativamente tratada como manifestação nacionalista de arquitetura como a historiografia mais tradicional fez (BRUAND, 1991). Assim, convém mostrar que o movimento defendido por José Marianno Filho era, de fato, o reflexo brasileiro de um processo verificado em todos os países do continente americano, com exceção do Canadá. Apoiados em discursos localistas, cada país das Américas onde o "estilo tradicional" floresceu não pretendia simplesmente transportar do passado para o presente os mesmos programas e técnicas construtivas encontrados anteriormente. $\mathrm{O}$ que este movimento de práxis pan-americanista postulava era a necessidade de atualização das imagens e das proporções arquitetônicas verificadas na época colonial, em face dos avanços tecnológicos na área da construção civil e nos

\footnotetext{
${ }^{4}$ Wilson Ricardo Mingorance, graduando em História no Departamento de História da UNIFESP tem desenvolvido pesquisa que compila os textos de José Marianno Filho publicados tanto em livros quanto na imprensa seriada. Por meio dessa pesquisa, ainda em andamento, já foi possível perceber quão profícua foi essa discussão no cenário nacional das décadas citadas (MINGORANCE, 2011).
} 
modos de vida. José Marianno Filho revela tal preocupação ao escrever que "os arquitetos poderiam aprender essas verdades [de que não há estilo arquitetônico sem utilidade e de que não há utilidade sem lógica e raciocínio] não para fazerem o estilo colonial, pesadelo dos carapinhas patrícios e dos mestres de obras (...), mas para fazerem coisa melhor do que os portugueses fizeram" (CUNHA FILHO, O Jornal, 8 de jul, 1931, s.p.). Para ele, "o problema da arquitetura brasileira" precisava ser equacionado diante dos "eternos fatores mesologico-sociaes da propria nacionalidade" (CUNHA FILHO, O Jornal, 8 de jul, 1931, s.p.). 


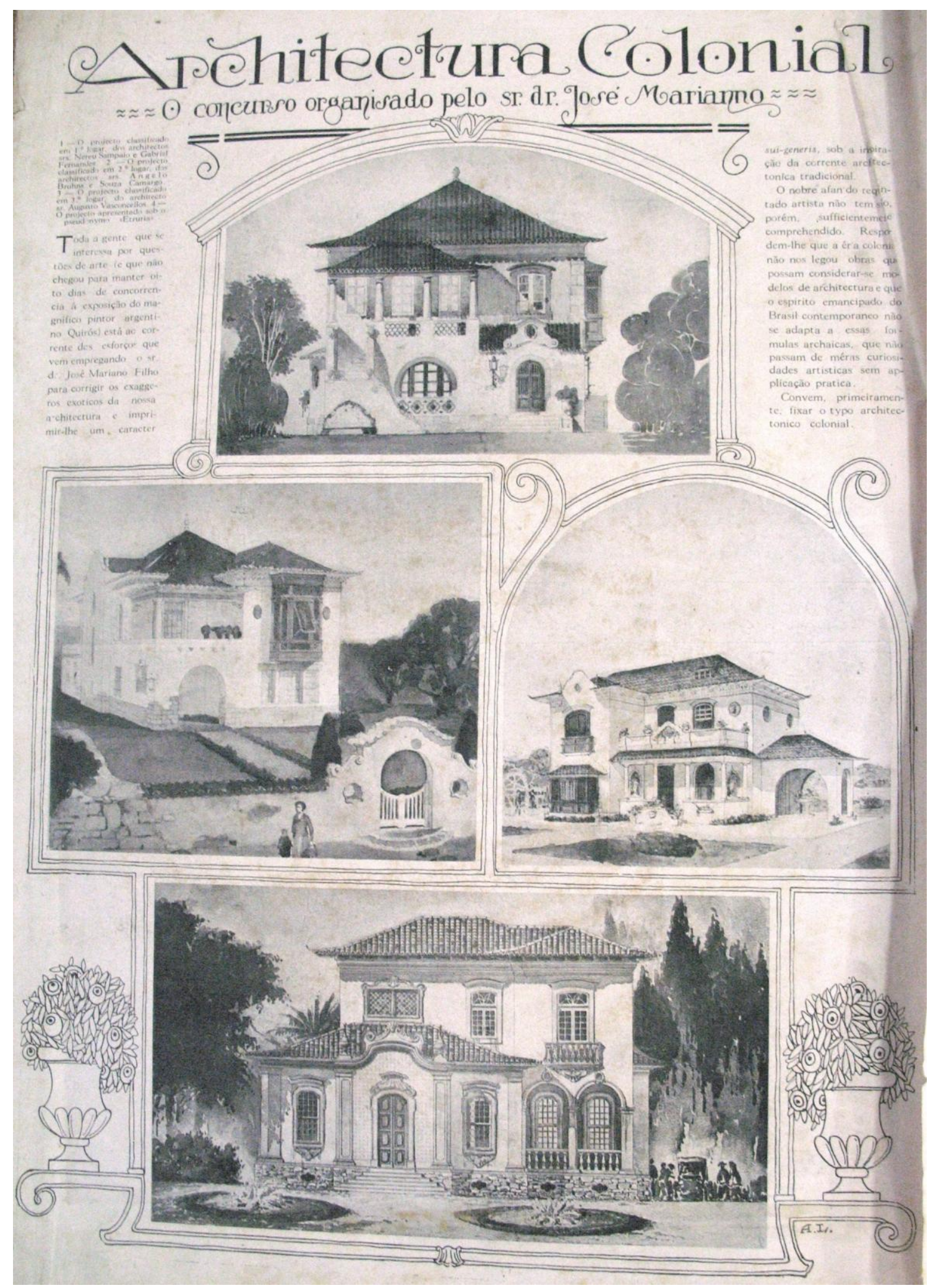

FIGURA 1:

"Architectura Colonial".

Fonte: Revista da Semana, 22 de outubro de 1930. 
Curiosamente, como já apontou inclusive Yves Bruand, foi por ação de um português radicado em São Paulo que o primeiro lastro desta campanha neocolonial aconteceu no Brasil, anos antes da entrada de José Marianno nesta campanha. O ponto seminal do neocolonial, assim, é tratado como tendo sido a comunicação do engenheiro português Ricardo Severo junto à Sociedade de Cultura Artística de São Paulo, em 20 de julho de 1914, batizada de A Arte Tradicional no Brasil: a Casa e o Templo. Nesta conferência Ricardo Severo expôs a necessidade de que o Brasil recuperasse sua trajetória arquitetônica interrompida com a eclosão do ecletismo, tese que também seria defendida intensamente por José Marianno Filho, como já visto. Entretanto, afirmava Severo, por outro lado, que a ação a ser tomada nessa produção arquitetônica era a de reinterpretar e de revalorizar a arquitetura erudita de origem portuguesa, realizada diligentemente por lusitanos, no país, durante o período colonial. Como pontuou Ricardo Marques de Azevedo, "em resumo, o que Ricardo Severo afirmava era que a cultura autóctone que existia em terras brasileiras, por sua insipiência e primitivismo, não tinha a força suficiente para fundamentar uma arte de caráter nacional" (AZEVEDO, 1994, p.294). Ora, essas declarações nos revelam que a arquitetura pensada por Severo não era recuperadora da arquitetura anônima, civil ou "aclimatada" do Brasil Colônia, como colocava José Marianno Filho, mas, sim, de sua ascendência portuguesa. Era neocolonial, pelo que se depreende dos escritos de Severo, na concepção política deste termo: a de restabelecer uma dialética entre "metrópole lusa" e “colônia brasileira” (SEVERO, 1914, ATIQUE, 2010).

Os discursos de Ricardo Severo e de José Marianno Filho, assim, embora possam ser arrolados dentro de uma mesma categoria - a propugnação da arquitetura de fundo tradicional - mobilizavam repertórios diversos de argumentação e de formas plásticas. Para Severo era a arquitetura erudita, mais assentada e diligentemente riscada por portugueses que deveria ser a fonte para a "nova arquitetura"; para Cunha Filho, por outro lado, era a cidade colonial, com suas convivências entre obras opulentas e casas vetustas.

Em certo sentido, com essas considerações, parte da resposta à indagação lançada linhas atrás aparece. A razão de repudiar a ideia de uma arquitetura que se propunha como "anacrônica", pejorativamente chamada de "eclética", vinha proteger a arquitetura nacional da associação imediata com Ricardo Severo, ou seja, do português zeloso dos feitos de seus patrícios, antigos colonizadores do Brasil, em plena década de pensamentos nacionalistas e xenófobos. Entretanto, convém apontar que esta é apenas 
uma das saídas para o problema lançado por este artigo. Ora, não se tratava apenas de proteger a arquitetura recuperadora da sensibilidade e da estética colonial das investidas xenófobas. Tratava-se, de fato, de cercear os escambos de formas que em sua proliferação tal arquitetura encontrou.

Para desenvolver este raciocínio é pertinente mostrar que, contrariando a genealogia corrente acerca do "neocolonial brasileiro" que aponta, em um primeiro momento a) a conferência de Ricardo Severo, em 1914, como ponto seminal; e, b) a construção de duas residências, por Severo, com repertório formal português, antes da conferência de $1914^{5}$, de que alguns anos antes, em 1907, em Washington D.C., a dupla de arquitetos atuantes nos Estados Unidos, Paul Philippe Cret e Albert Kelsey, projetaram a sede da Pan American Union, hoje Organização dos Estados Americanos, promovendo uma fusão de características que pudessem expressar a diversidade do continente americano (GROSSMAN, 1996, p.27-43). Esta obra, também chamada de Casa das Américas, é, de fato, uma das primeiras realizações com o conceito neocolonial no continente americano. É ela, inclusive que, embora não totalmente explícita em suas fachadas, inaugura uma tradição de pesquisas acerca do ambiente arquitetônico em perspectiva histórica como baliza para a feitura de arquiteturas neocoloniais nos Estados Unidos (ATIQUE, 2010).

\footnotetext{
5 Trata-se das casas geminadas das ruas Piauí e Maranhão, datadas de 1910 (LEMOS, 1993, p.85; WOLFF, 2000, p.221) -
} 


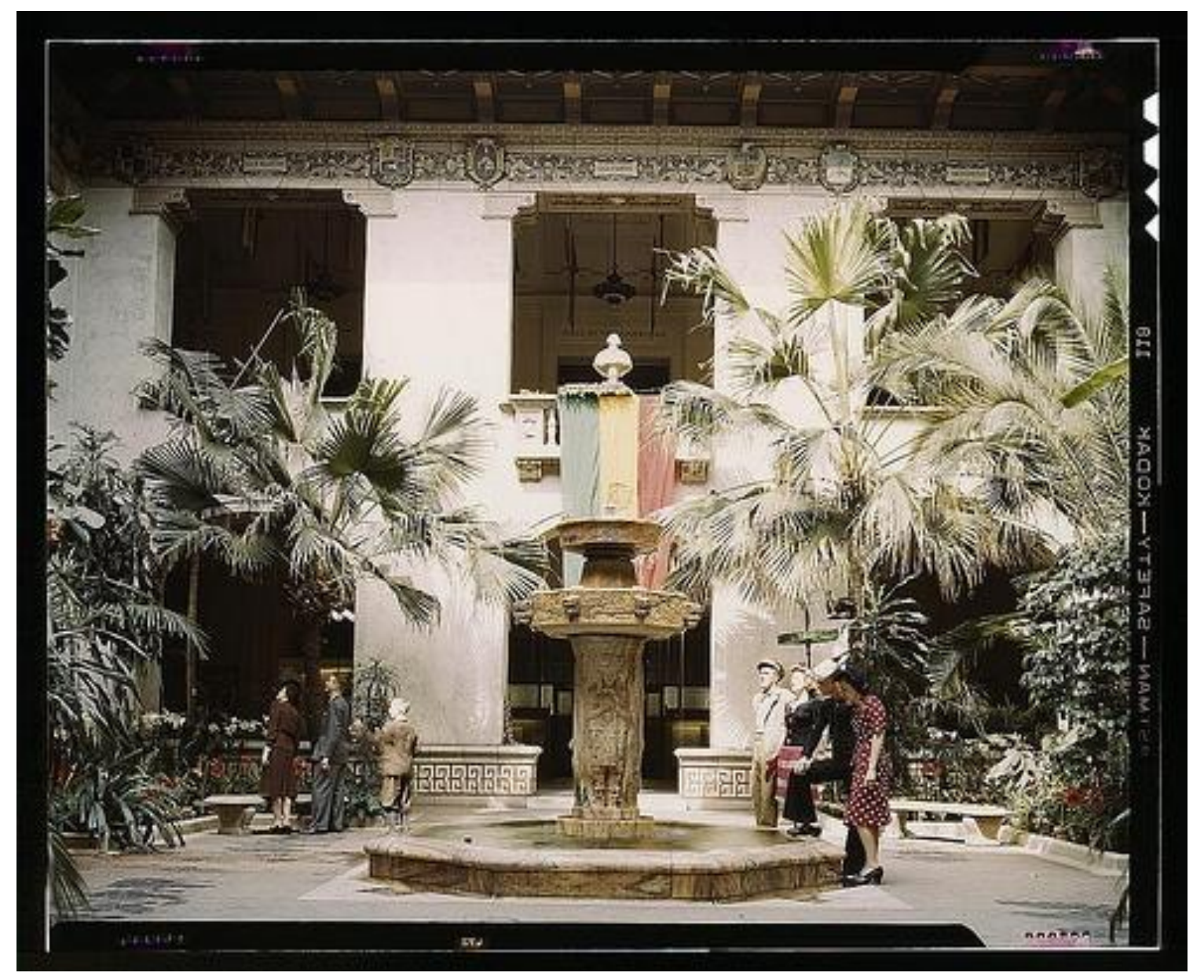

FIGURA 2:

Pátio do "Pan American Union Building", de 1907.

Foto: John Collier. Disponível em:

http://www.flickr.com/photos/library_of_congress/2179927806/

Assim, é interessante notar que Albert Kelsey empreendeu uma pormenorizada viagem de estudos ao México durante a feitura desse projeto para coletar referências ornamentais da arquitetura inca, mas também da hispânica, que foram empregadas, efetivamente, no pátio interno da atual sede da OEA (CARTAS DE ALBERT KELSEY PARA PAUL CRET, Ms. Coll. 295). Este projeto de Cret e Kelsey tornou-se amplamente conhecido nos Estados Unidos, especialmente pelo uso do espaço pela Pan American Union, que promovia sistemáticas reuniões entre as Repúblicas Americanas e publicava boletins de caráter pan-americanista, trazendo fotografias de sua sede e remetendo-os a todo o continente. Além disso, segundo Elizabeth Grossman, o projeto em tela se difundiu pelos Estados Unidos pelo fato de muitas publicações americanas terem enfocado o edifício (GROSSMAN, 1996, p. 27-43). 
Dessa forma, embora ainda não tenhamos encontrado nenhum documento irrefutável que ligue Severo ao conhecimento prévio dessa edificação americana, sustenta-se que é muito plausível que ele tenha conhecido a obra por meio dessas publicações, pois fazia parte do círculo de arquitetos do Escritório Técnico Ramos de Azevedo, e desenvolvia ali atividades de construções com grupos de políticos, estrangeiros e nacionais.

Um outro ponto nodal à argumentação que se faz neste artigo diz respeito à detecção da existência, na historiografia que trata do neocolonial na arquitetura, de certa condescendência com o discurso de Severo. Quase nunca se fala que a arquitetura por ele pretendida era estrangeira ou exógena - nem mesmo por José Marianno Filho -, apesar de suas manifestações textuais explícitas e implícitas de que o fundo repertorial para a feição da arquitetura tradicional no Brasil era o Porto, e não Ouro Preto. Algo que se percebeu foi que a não-incorporação de Severo ao rol dos estrangeiros que produziam discursos e "arquiteturas exóticas" se dá pela "maturação" de seu discurso, entre 1914 e 1922. Durante esses anos Severo foi explicitando, com mais apuro, a ideia de que a raça brasileira era tributária direta do mundo português, e que o recuperar das ligações artísticas com Portugal não era um demonstrativo de uma atitude de dominação ou a assinatura de um atestado de dependência, mas, sim, o retirar da arquitetura brasileira "de um período de decadência" cujo despertar se mostrava tardio (SEVERO, 1922). Essa vertente sociológica era defendida por diversos pensadores brasileiros naquele momento de definição de origens, e se coadunava à tese de Oliveira Vianna sobre o "paulista", em certo sentido.

Para além dessa questão, deve-se notar, também, que Severo tinha consciência do que vinha ocorrendo em outros países e intentava inserir o Brasil no mesmo patamar dessas nações. Ele diz, textualmente, que, enquanto o Brasil permanecia na letargia arquitetônica, nos “outros países [amanhecia] uma nova renascença nacionalista, com o apostolado da tradição, de uma arte que [realizava] a arquitetura da raça na sua essência tradicional" (SEVERO, 1922). Ele fazia menção, nesta citação, a Portugal, que vivia uma produção nacionalista e tradicional de arquitetura em fortes bases naquele momento, mas remetia, também, aos países da América, sobretudo Argentina, Chile, México e Estados Unidos que desenhavam, literalmente, formas de ligação do passado colonial com a república em plena época de centenários de independência (ATIQUE, 2010). Assim, o discurso de Severo não era interpretado como xenófobo ou neocolonialista nem por seus contemporâneos, nem por diversos historiadores, pelo fato 
de sustentar a tese de que era na busca das origens coloniais brasileiras que se encontraria o elo perdido da verdadeira arte. Este elo - como quase que “messianicamente" já havia advertido - era a herança portuguesa, o que era inegável, de fato, ao brasileiro. Por outro lado, ao inscrever esta busca num cenário internacional, respondia ao afã modernizador e internacionalista típico da sociedade industrial que já estava arraigada no país. Em suma: era por meio do encontro com o passado que se estabeleceria a condição para o ingresso brasileiro no cenário internacional. De certa forma, Severo passou a se valer da mesma estratégica de argumentação de José Marianno Filho, embora recorresse a peças argumentativas diversas.

Esta constatação é importante, pois, se era buscando as origens que se ingressaria no universo artístico internacional, seguindo os mesmos passos dos demais países americanos, era possível tentar encontrar características comuns entre o Brasil e as outras nações do continente americano. Entretanto, Severo, num primeiro momento, e José Marianno Filho, depois, se pronunciariam contrários a este crescente "escambo de formas" entre os países de origem hispânica e o Brasil. Ambos, já nos anos 1920, explicitaram a necessidade de se pesquisar e estabelecer normas para a utilização rigorosa e parcimoniosa dos elementos artístico-arquitetônicos do passado nacional. E mais, para ambos, era necessário combater o interesse pela arquitetura dos vizinhos americanos e sua elevação à categoria de "modelos" de arte e de arquitetura (SEVERO, 1922).

Neste sentido, José Marianno Filho comentando a Exposição do Centenário da Independência do Brasil, ocorrida no Rio de Janeiro, em 1922, declarou a propósito da obra de reforma da Antiga Casa do Trem pelos arquitetos Memória e Cuchet o seguinte:

\footnotetext{
"Levantaram-se tímpanos mesquinhamente perfilados, compuseram-se bowwindows inglesas à guisa de elementos decorativos (quer dizer que o Senhor Cuchet ignorava que nós possuíamos lindos balcões almofadados, aliás, comuns à toda América Latina), forjaram-se grades com escudos de renascimento espanhol, cometeram-se barbarismos e enxertos, na ânsia de embelezar um estilo cuja beleza está apenas na sua simplicidade" (CUNHA FILHO, citado por KESSEL, 2008, p.107).
}

Agora se pode tentar responder à pergunta lançada linhas atrás de forma mais densa: "qual era a motivação para tamanho debate e tantas precauções para com a designação dessa forma de arquitetura?”

Bem, de pronto, pode-se mostrar que o sistema de educação de arquitetos, no Brasil, valia-se de repertório visual e de literatura internacional, primeiramente porque a 
produção de livros técnicos para o ensino superior era muito pequeno (ATIQUE, 2005), depois, porque consideravam-se os métodos de ensino quase universais (PEREIRA, 2005). Dessa forma, problemas colocados para a produção arquitetônica brasileira nas décadas de 1910, 1920 e 1930 eram muito semelhantes daqueles da vertente de ensino das academias e escolas de arquitetura dos países americanos e até europeus. Assim, intelectuais como José Marianno Filho, atentos à campanha neocolonial e à suplantação da tendência beauxartiana de produção do espaço, deparavam-se, constantemente, com manuais bem elaborados de seleções métricas, fotográficas e textuais de casas e demais edifícios feitos em consonância com preceitos "nacionalistas", mas provenientes, sobretudo, da Argentina e, em larga medida, dos Estados Unidos, mas facilmente adquiridos no país (ATIQUE, 2010). Este é um caso de pan-americanismo que pouco foi registrado e que teve para o episódio do neocolonial, fator preponderante, contudo.

Um exemplo eloquente do que acima se afirmou, é o ocorrido em 1925, com o convite para a participação do Brasil na feira que comemoraria os 150 anos da Declaração da Independência dos Estados Unidos, a ocorrer na Filadélfia. O resultado do concurso organizado pelo Itamaraty permite ver que os arquitetos, sobretudo os do Rio de Janeiro, recorreram à fusão de referências do colonial luso-brasileiro com o do hispano-americano para a concepção dos espaços e das ornamentações de seus projetos. Por meio do arquivo do arquiteto Paulo Santos, que durante algumas décadas amealhou recortes de jornais sobre o que se publicava no campo da Arquitetura, do Urbanismo e das Artes, em geral, no Brasil, pode-se verificar as propostas submetidas a essa seleção. De fato, embora Lucio Costa tenha sido indicado vencedor no certame, como apontou o próprio Paulo Santos, em Quatro Séculos de Arquitetura, foi a proposta riscada por Edgard Vianna ${ }^{6}$ e Raphael Galvão que acabou se tornando célebre. Isso se deu por conta de a dupla ter realizado, exatamente, uma fusão de elementos arquitetônicos do Brasil colonial com nítidas ornamentações hispanas, encontradas em manuais de arquitetura publicados nos Estados Unidos (SANTOS, 1981, p.94, ATIQUE, 2011). Assim, na visão de Marianno Filho, um fator palpável para o possível desvirtuamento de sua proposta nacionalista estava posto: o contato com os Estados Unidos e com sua indústria editorial que, já nos anos 1920, invadia o país com inúmeras revistas, álbuns e

\footnotetext{
${ }^{6}$ Edgard Pinheiro Vianna nasceu no dia 3 de setembro de 1895, em Campos dos Goytacazes, no estado do Rio de Janeiro; ele era filho de José Maria Vianna e de Maria Theresina Pinheiro Vianna. Apesar de fluminense, Vianna morou, durante toda a infância e adolescência, na cidade do Rio de Janeiro. Com 18 anos, nos primeiros meses de 1914, frequentou a Escola Nacional de Belas Artes, - ENBA -, no Rio de Janeiro, mas logo no ano seguinte mudou-se para os Estados Unidos, onde acabou concluindo o curso de Arquitetura, em 1919, University of Pennsylvania - Penn. Sobre Edgard Vianna, conferir ATIQUE, 2011.
} 
propagandas acerca do que o brasileiro daqueles anos chamava de "bangalô californiano" (NASLAVSKY, 1998, p. 75).

Em termos compositivos, afinal, qual era o problema detectado por José Marianno Filho com respeito à assimilação do neocolonial de matriz luso-brasileira com o de proveniência hipano-americana? A pesquisa realizada junto às três principais escolas formadoras de arquitetos e engenheiros do Brasil, entre 1894 e 1945 - a Escola Politécnica de São Paulo, hoje pertencente à USP; a Escola Nacional de Belas Artes, atualmente integrante da UFRJ; e o Mackenzie College, hoje Universidade Presbiteriana Mackenzie - revelou que os temores desses intelectuais eram plenamente materializados nas estantes dessas instituições de ensino.

\section{Algumas Escolas de Arquitetura do Brasil com "Repertórios Neocoloniais"}

Embora possam ser encontrados estudos acerca das instituições brasileiras ligadas à formação dos profissionais do espaço construído com relativa facilidade, é muito raro encontrar estudos que tenham analisado a fundo os acervos das antigas bibliotecas dessas instituições. Neste artigo, sistematizam-se apenas algumas informações que dão suporte à argumentação de que referências americanas ajudaram a modificar a imagem postulada por Ricardo Severo e José Marianno Filho para o movimento neocolonial.

Se tomarmos como ponto de partida a antiga Escola Nacional de Belas Artes ENBA - do Rio de Janeiro, a instituição de ensino mais antiga dentre todas as investigadas $^{7}$, perceberemos a existência de farto material americano na instituição. A pesquisa revelou que havia livros editados em 1897 e 1902 destinados às aulas de

\footnotetext{
${ }^{7}$ A ENBA tem sua origem na Academia Imperial de Belas Artes - AIBA - que passou a ministrar o curso de arquitetura em 1827, ano em que seu funcionamento foi oficialmente autorizado. Este ensino tinha, como um dos lentes principais, Auguste Henri Victor Grandjean de Montigny, arquiteto laureado pela École de Beaux-Arts de Paris, em 1799, e ganhador do Grand-Prix de Rome. Sabe-se que, com a Proclamação da República, o curso sofreu alteração significativa, recebendo, inclusive, no começo do século XX, uma nova sede, construída na Avenida Central, então recém-aberta por Francisco Pereira Passos. Também sob a República, houve a separação dos cursos artísticos (pintura, desenho, escultura) do curso "aplicado" (arquitetura) se tornou mais nítida, chegando a estipular exame admissional específico para a carreira arquitetônica. Até 1945, a ENBA ofereceu o curso de Arquitetura na sua sede da Avenida Central, nesse período já chamada de avenida Rio Branco. A partir de 1945, contudo, este curso deu origem à Faculdade Nacional de Arquitetura, criada pelo decreto n. 7918, de 31 de agosto, a qual passou a funcionar na Praia Vermelha, no casarão que antes abrigava o Hospício Pedro II. Até 1961, a Faculdade de Arquitetura esteve locada na Praia Vermelha, quando, juntamente com outros cursos da, então, Universidade do Brasil, foi transferida para o campus da Ilha do Fundão, passando a se chamar Faculdade de Arquitetura e Urbanismo. Até hoje, a designação e a sede permanecem as mesmas (ATIQUE, 2010).
} 
topografia $^{8}$, mas também, outros títulos, como o livro de Russell Sturgis, de nome $A$ Dictionary of Architecture and Building: biographical, historical, and descriptive by and many Architects, Painters, Engineers, and other expert writers, American and Foreign, publicado em Nova York pela MacMillan, em 1901. Com relação às revistas voltadas à arquitetura foram localizados exemplares da Architectural Record, editada em Boston, desde 1876, primeiramente sob o nome The American Architect and Architecture e, depois de 1910, já com esta designação. O acervo desta revista na biblioteca da antiga ENBA iniciou-se em 1912, no número 31, e está completo até os dias de hoje. O significado da Architectural Record para a divulgação do neocolonial de matriz hispano-americana, chamado de mission style ou estilo missões, foi grande. Assim como muitas revistas estadunidenses, a Architectural Record, também foi portavoz dos estilos historicistas e do modernismo, dedicando reportagens inteiras ao movimento de construção de edifícios dentro do repertório do mission style. Em 1922, por exemplo, o número de janeiro trouxe reportagem sobre a residência J.P. Jefferson, em Montecito, Califórnia, projetada pelo arquiteto Reginald D. Johnston, de feições tipicamente missões (ARCHITECTURAL RECORD, Jan, 1922, p.8-15). O número de julho dedicou 21 páginas para abordar os projetos recentes do escritório de Marston \& Van Pelt, atuante no sul da Califórnia, e mostrou quatro projetos completos vinculados ao mission style, além de muitas fotografias das obras (ARCHITECTURAL RECORD, 1922, Jul, p.17-38), para citar apenas alguns casos elucidativos da abundância desta temática.

Além da Architectural Record, localizaram-se números da revista Architectural Digest, no entanto sem volumes sequenciais. A edição mais antiga remonta a 1920. Esta revista possui, até os dias de hoje, como estrutura, a mescla de reportagens sociais com a publicação de projetos de arquitetura. A Architectural Digest, produzida, desde 1914, em Los Angeles, pela California Knapp Communications Corporation, também abordou projetos de formas hispânicas, em diversos números, ao longo dos anos.

Junto dessas revistas não tão abundantes na ENBA, estão os livros técnicos estadunidenses, estes, sim, mais numerosos. Extremamente importante é a presença dos livros de Paul Harbeson", no acervo da ENBA: The Study of Architectural Design, with

\footnotetext{
${ }^{8}$ Como os de Henry A. Reed, intitulado Topographical Drawing and Sketching, Including Applications of Photography, publicado em Nova York por John Willey \& Sons, e o A Manual of Topographical Drawing, de Lieut Smith, editado pela já referida John Willey \& Sons, em 1902.

${ }^{9}$ John Frederick Harbeson, nascido em 1888, foi um arquiteto diplomado pela Penn em 1910, o qual teve trajetória profissional e afetiva muito próxima de Paul Philippe Cret, tornando-se colaborador, após a I
} 
Special Reference to the Program of the Beaux-Arts institute of Design, publicado em Nova York pela Pencil Points, em 1927, e Winning Designs, 1904-1927, Paris Prize in Architecture, editado pela mesma companhia, em 1928, no qual são expostos projetos criados dentro das regras "beauxartianas", mas com várias referências hispânicas, aos moldes do Pan-American Union Building, de Paul Cret e Albert Kelsey.

Embora os livros de Harbeson sejam importantes, não são comparáveis aos produzidos por Rexford Newcomb ${ }^{10}$, o principal divulgador da história e dos edifícios criados dentro do vocabulário hispânico, nos Estados Unidos. Na ENBA foi possível encontrar volumes do Spanish House for America. Este livro, publicado pela editora J.B. Lippincott, da Fildélfia, tornou-se muito popular no Brasil, nos anos 1930, e foi, sem sombra de dúvida, uma das principais referências para o projeto de edificações dentro dos princípios coloniais hispano-americanos, em todo o continente (ATIQUE, 2010). Sua presença na biblioteca da instituição revela o porquê de muitos projetos realizados pelos egressos da ENBA mostrarem um apurado senso compositivo e de detalhamento. Sabe-se, todavia, que o rigor projetual dos alunos foi também alcançado pela consulta a outro título importante, o Architectural Details of Southern Spain: One Hundred Measured Drawings, One Hundred and Thirteen Photographs, trabalho de Thomas Gibson e Gerstle Mack, publicado, em Nova York, em 1928, que apresenta um verdadeiro arsenal de modelos para detalhamento da arquitetura missões.

Na mesma linha, localizou-se outro livro, de nome Measured Drawings of Early American Furniture, da pena de Burl N. Osburn, de 1926, que trazia, dentre muitos desenhos ligados a outros estilos arquitetônicos, referências ao mobiliário de caráter hispânico.

Guerra, e sócio, a partir de 1923, no escritório que Cret mantiveram antes com Albert Kelsey (ATIQUE, 2011).

\footnotetext{
${ }^{10}$ Nascido em 1886, em Independence, no estado norte-americano do Kansas, Newcomb formou-se, em 1911, no curso de arquitetura da University of Illinois, depois de ter frequentado, até 1908, a universidade de seu estado natal. Já arquiteto e casado, em 1912, mudou-se para a Califórnia, onde abriu um escritório, seguindo os passos de muitos arquitetos recém-formados nos Estados Unidos, que eram atraídos pelas possibilidades imobiliárias da costa oeste. Ali, ele começou a lecionar, junto à Long Beach Polytechnic for Adults. Em 1917, Newcomb recebeu o grau de bacharel em Sociology and Political Science, pela Universidade da Southern California, em Los Angeles. Neste mesmo ano o arquiteto se mudou para lecionar no Texas Agricultural and Mechanical College, em seu Departamento de História da Arquitetura. Em 1918, a University of Illinois concedeu-lhe o título de Mestre em Arquitetura e o convidou a desenvolver, ali, carreira como professor. Em 1931, ainda em Illinois, ele organizou o College of Fine and Applied Arts, tornando-se seu diretor até 1954, quando se aposentou. Durante sua carreira como educador, Newcomb publicou 250 artigos e 18 livros, quase todos devotados ao estudo das heranças arquitetônicas provenientes do período colonial dos Estados Unidos, sobretudo daquela encontrada em territórios que foram colonizados por espanhóis (APPLETON, 1999, p.XIV).
} 
Outro título digno de nota, encontrado no acervo da ENBA, é American Public Buildings of Today, de 1931, escrito por Randolph Sexton. Este livro mostra quase uma centena de projetos executados dentro dos referentes hispano-americanos de escolas, hospitais, creches, além de outros programas de edifícios institucionais. A nota curiosa é que a publicação enfatiza que muitas dessas edificações foram fruto de um trabalho de reconstrução, empreendido pelo Governo Federal daquele país, nos estados da costa oeste, após diversos abalos sísmicos que dizimaram a arquitetura preexistente ali, sobretudo o de 29 de junho de 1925, que acabou com o centro de Santa Bárbara (SAGARENA, 2002, p.429).

Se havia fontes para apreensão da arquitetura missões, dentro da ENBA, não se deve esquecer de apontar o valioso acervo encontrado na Biblioteca Central da Escola Politécnica. Em um universo de obras germânicas, francesas e inglesas, a atual Escola Politécnica da USP possui em seu acervo publicações americanas que permitem atestar as fontes de projeto e de erudição utilizadas pelos graduandos e pelos professores, desde fins do século XIX. ${ }^{11}$ Dentre os títulos lá encontrados, procedentes dos Estados Unidos, figuram obras como: American Renaissance: a Review of Domestic Architecture, escrita por Joy Wheeler Dow e editada pela Comstock, de Nova York, em 1904; a revista Domestic Engineering, editada em Chicago e com números que remontam a 1900, no acervo, e o periódico The Craftsman, que remete ao ano de $1905 .{ }^{12}$ Fora estas, figura, também, o mensário American Architect and Architecture, editado em Boston, desde 1876 - absorvido, posteriormente, pela revista Architectural Record, - e cujo primeiro volume encontrado na EPBC remonta a 1891. Foi possível detectar, ainda, os títulos: $A$ Dictionary of Architecture and Building: Biographical, Historical, and Descriptive by and many Architects, Painters, Engineers, and other Expert Writers, American and Foreign, da lavra de Russell Sturgis, de 1902; e a Encyclopedia of Architecture, Carpentry and Building, obra de Henry Barnard. Todavia, o que mais chamou a atenção

\footnotetext{
${ }^{11}$ Segundo o relatório encaminhado pelo Diretor da Escola Politécnica, Paula Souza, em 14 de janeiro de 1895, ao "Secretário dos Negócios do Interior, Dr. Cezario Motta Jr.", e recuperado por Maria Cecília Loschiavo dos Santos, a biblioteca da Politécnica possuía, naquela data: "489 volumes, integrado por livros de ciências, artes, revistas, dicionários, enciclopédias, relatórios, folhetos diversos e as coleções das leis e do Diário Oficial do Estado" (SANTOS, 1985, p.382). A biblioteca iniciou suas atividades em 1895, sob o comando do engenheiro-bibliotecário Eugenio Alberto Franco. Em 1907, a autora em questão apontou que o acervo havia subido para 6.442 volumes e, em 1982, possuía 47.202 volumes (SANTOS, 1985, p.382).

${ }^{12}$ A revista The Craftsman, produzida em Syracuse, estado de Nova York, publicou, como relata Marc Aplleton, "uma variedade de artigos que alimentou, também, a produção do American Spanish, nos Estados Unidos". (APPLETON, 1999, p.XII).
} 
foi a descoberta do livro The Franciscan Mission Architecture of Alta California, escrito por Rexford Newcomb, em 1916, e da revista Pacific Coast Architect and Building Review, de 1924, transformada, depois, em California: Arts and Architecture, cuja coleção principia em 1929 e segue até 1943.

É bem compreensível o porquê de estarem estes títulos nas estantes da Escola Politécnica, uma vez que a maioria de seus professores eram os mais importantes divulgadores dos estilos historicistas em São Paulo, em nosso arco temporal de pesquisa (1907-1950). Por outro lado, deve-se frisar que a existência de títulos americanos na instituição paulistana demonstra que não havia um foco de interesse apenas sobre a produção europeia, e revela uma multiplicidade de olhares por parte da instituição paulistana, dentro do mundo tecnológico e artístico, extremamente enriquecedor.

Contudo, deve-se fazer uma ressalva: uma parcela de títulos encontrada na Politécnica pertenceu a antigos professores. Isto, entretanto, não anula, nem inviabiliza as conclusões obtidas, haja vista a intenção maior deste tópico de entender as referências americanas que circularam pela casa, seja por meio do corpo discente ou docente. Muitos livros e periódicos que outrora pertenceram ao arquiteto Ramos de Azevedo, co-fundador da instituição, foram acoplados ao acervo da Biblioteca após sua morte, em 1928, por sua própria recomendação (CARVALHO, 2000).

Entretanto, surpresa mesmo acontece com o exame das revistas Pacific Coast Architect and Building Review e California: Arts and Architecture. A primeira surgiu em 1924, a partir de um periódico de nome Building Review, publicado em São Francisco, desde 1919. ${ }^{13}$ Em 1924 houve a criação da Pacific Coast Architect, que incorporou não apenas a estrutura da antiga revista, como seu próprio nome. A Pacific Coast Architect tinha um caráter muito semelhante ao da sua antecessora, que era o de divulgar textos, fotografias e reportagens ligadas ao setor da construção civil, principalmente, dos que eram intimamente ligados à atribuição profissional do arquiteto: projeto, construção, pesquisa dos referentes estéticos e paisagismo. A Pacific Coast Architetc and Building Review era uma revista dirigida ao meio técnico arquitetônico, como seu slogan denunciava: "uma revista mensal, ilustrada, para o arquiteto, o empreiteiro e o construtor habitacional". Assim, a Pacific Coast Architect and Building Review atinha-se a historiar o desenvolvimento da macro área Los Angeles - São Francisco publicando, consequentemente, inúmeras fotografias de antigas missões

\footnotetext{
${ }^{13}$ A Biblioteca Central da Escola Politécnica possui todos os volumes deste periódico, desde 1919.
} 
franciscanas; muitos projetos vazados dentro dos estilos históricos encontrados na Califórnia, e textos nos quais a questão sobre a atividade projetual do arquiteto daquela costa era apontada como diversa da encontrada ao longo do litoral Atlântico dos Estados Unidos.

A revista persistiu com este nome até 1929, quando se tornou California: Arts and Architecture pela fusão com outra publicação, a California Southland, que possuía um caráter mais próximo do que se conhece, atualmente, por revista de variedades.

O teor editorial da California: Arts and Architecture não era muito diverso do de suas antecessoras, uma vez que mesclava reportagens sobre personalidades de toda a Califórnia e sudoeste americano com programas culturais e, ainda, com reportagens extensas sobre casas de artistas de cinema e de políticos. O destaque às edificações e aos produtos "típicos da Califórnia" possibilitou a divulgação de plantas e fotografias de casas, de missões, de praias, de edifícios de estações de trem, de museus e de cinemas, os quais, certamente, alimentaram as turmas da Escola Politécnica de repertório sobre a arquitetura daqueles lugares e, em especial, da vinculada ao mission style. Esta afirmação se faz pelas semelhanças encontradas nas obras identificadas como sendo de alunos da Poli, quer por meio das revistas, quer em levantamento de campo pelas ruas de cidades do estado de São Paulo.

Estes periódicos citados podem ser vistos como atestados da fonte repertorial americana na Escola Politécnica, para a apreensão da arquitetura mission style. Depois da Segunda Guerra, a revista mudou novamente seu nome para Arts and Architecture, tornando-se uma das principais divulgadoras da Arquitetura Moderna "apropriada aos climas sub-tropicais", com as Case Study Houses (IRIGOYEN DE TOUCEDA, 2005). ${ }^{14}$

Por fim, se essas instituições que guardavam relações de ensino com o universo europeu mais detidamente, nos permitem mostrar a pluralidade de títulos capazes de repertoriarem a produção do neocolonial, o que não esperar do Mackenzie College, fundado e dirigido por educadores americanos e com professores de arquitetura com formação nos Estados Unidos? Analisando o acervo da biblioteca da atual Faculdade de

\footnotetext{
${ }^{14}$ Em 1944, a revista suprimiu o California de seu título e prossegui como Arts and Architecture, até fins da década de 1960. No período da Guerra, e, sobretudo, após seu término, a publicação passou a veicular reportagens afinadas com as questões da casa mínima e do alojamento para os soldados que regressavam à sua pátria. Neste momento, o mission style saiu de cena em prol das Case Study Houses, trabalhadas por Adriana Irigoyen em seu doutorado, demonstrando que não cessou o intercâmbio de modelos domésticos dos Estados Unidos com o Brasil depois da Guerra (IRIGOYEN DE TOUCEDA, 2005).
} 
Arquitetura e Urbanismo, o acervo do Centro Histórico e a Biblioteca George Alexander, esta, a mais antiga da Universidade Presbiteriana Mackenzie, conseguiu-se obter um panorama dos títulos que estiveram disponíveis entre 1917 - ano de formação do curso de Arquitetura - e 1950, quando termina o arco temporal desta pesquisa. Como era esperado, muitos títulos relativos à arquitetura clássica, editados nos Estados Unidos, foram encontrados, mas, não apenas eles, deve-se frisar. Volumes ligados à difusão do modernismo também foram achados e, o que interessa de forma especial a este texto, algumas obras ligadas ao repertório hispano-americano.

Começando pelos títulos que fornecem elementos sobre esta arquitetura pode ser citado o livro de John Haberson: The Study of Architectural Design, with Special Reference to the Program of the Beaux-Arts Institute of Design, de 1926. O fato de ter sido encontrado este livro nas três instituições pesquisadas demonstra como as referências estadunidenses para formação em arquitetura circularam pelo continente americano. Fora este título, alguns mais antigos, possivelmente comprados na época da constituição da Escola de Engenharia, em 1896, também foram localizados, tais como o escrito por James Carter Beard, de nome Curious Homes and their Tenants, publicado em Nova York, em 1897 pela Appleton; e o da lavra de Nathaniel Hawthorne, chamado Our Old Home, lançado pela Houghton, de Boston, em 1907. Sobre o universo colonial americano, o acervo que esteve disponível para consulta de engenheiros e arquitetos incluía, por exemplo, o The Colonial House, escrito por Joseph Everett Chandler, e produzido pela McBride, de Nova York, em 1924, dentre outros.

As obras ligadas mais diretamente à divulgação do missões foram os livros, e não as revistas, no Mackenzie, como se poderia supor. ${ }^{15}$ Estes livros foram American Public Buildings of Today: City Halls, Court Houses, Municipal Buildings, Fire Stations, Libraries, Museums, Park and Buildings, escrito por Randolph Williams Sexton, de 1931, e os mais explícitos na divulgação do assunto: The Mediterranean Domestic Architecture in the United States, de Rexford Newcomb, editado pela Janson, de Cleveland, em 1928; Spanish Interiors, Furniture and Details, from the $14^{\text {th }}$ to the 17 th Century, escrito por Harold Donaldson Eberlein, e publicado pela Architectural Book de Nova York, em 1925. E, sobretudo, o The Architectural Digest: a Pictorial Digest of

\footnotetext{
${ }^{15}$ Em um dos números da Revista de Engenharia do Mackenzie College, publicada em 1915, é possível encontrar logo no sumário a seguinte seção: "Extractos úteis e curiosos de Revistas Americanas e Inglezas", comprovando o olhar sobre o mundo técnico europeu e estadunidense. (Revista de Engenharia do Mackenzie College, 1915, out, n.3).
} 
California's Best Architecture, de 1920, produzido pela John Brasfield, em Los Angeles, e publicado em três volumes.

A grande discussão suscitada por José Marianno Filho com relação ao ensino de arquitetura no Brasil dizia respeito, em um primeiro momento da campanha neocolonial, à persistência de modelos de ensino beauxartianos:

\begin{abstract}
“(...) na escola, aprendem os arquitetos a compor os estilos arquitetônicos, de acordo com uma serie de ponto de vistas convencionais. / A preoccupação acadêmica, é meramente artística, e para instruir os arquitetos na busca de efeitos de composição arquitetônica, elles se exercitam longo tempo a copiar e a compor, de acordo com as idéas do mestre e de qualquer sorte com o proprio sentimento artístico da Escola. Saídos da Escola, atordoados com a Grécia, fascinados pelo moderno, enveredam pelo caminho mais curto, na ansia de conquistarem posição e independência" (CUNHA FILHO, O Jornal, 8 de jul, 1931, s.p.).
\end{abstract}

Entretanto, outras duas situações seriam enfrentadas por ele: uma, dizia respeito ao "caminho curto" mencionado acima, em que ele via uma sequência de arquitetos praticando arquitetura de maneira a aplacar os desejos dos mais diversos clientes imbuídos de repertórios de morar vistos nas telas do cinema e nas páginas de inúmeras revistas de variedades. A outra, era a dificuldade de conseguir impedir a proliferação de revistas nacionais de construção, que, via de regra, eram publicadas mensalmente por desenhistas, e que divulgavam aspectos formais da arquitetura que propalava, facilitando, ainda mais, um percurso cuja condição basilar era a investigação de uma herança "nacional" construída ainda capaz de ser encontrada no país, em cidades de origem colonial.

\title{
Projetistas e Manuais de um Neocolonial Segundo o "Gosto Americano"
}

Mostraram-se, até aqui, alguns dos caminhos percorridos pela arquitetura neocolonial, especialmente pelo estilo missões. Tratou-se do universo acadêmico com a investigação da formação de repertório de docentes e de engenheiros e arquitetos. Entretanto, é necessário enfocar, também, a maneira como uma produção "erudita" de arquitetura se dissemina em uma sociedade receptiva, consolidando e amplificando a adesão a opções estético-formais. Esta recepção, no caso da análise do mission style, é importante, pois considerável parcela das edificações encontradas nos levantamentos de campo foi feita por mestres de obras e por construtores, sem a presença de um arquiteto ou engenheiro efetivamente diplomado. Estes mestres de obras e construtores realizaram uma "tradução espacial" de edificações vistas em revistas de construção, em 
filmes ou em outros prédios vazados por profissionais que receberam uma formação acadêmica e ampliaram as escalas de difusão do estilo missões, no Brasil, ao se coadunar à deles.

Desta forma, tentando entender, também, os caminhos não-acadêmicos percorridos pela arquitetura neocolonial de vertente hispano-americana, procedeu-se a uma investigação das publicações que, além de terem servido a engenheiros e arquitetos, voltaram-se, ainda, a mestres de obras e a potenciais proprietários, os quais ajudaram a disseminar, de norte a sul do Brasil, o mission style. Pelo exposto, convém tratar de algumas outras trajetórias que ajudem a compreender as razões dessa arquitetura ter sido encontrada em tantas regiões diversas. A primeira consideração, nesta linha, faz com que se retorne às instituições de ensino já analisadas para mostrar onde alguns de seus egressos atuaram profissionalmente.

Em pesquisa de campo realizada ao longo da década de 2000, constatou-se que a cidade de Campinas, no interior de São Paulo, apresentava muitas edificações vazadas dentro dos princípios do mission style. Por meio de pesquisa bibliográfica tomou-se ciência do importante trabalho de alguns arquitetos que atuaram na cidade. Um dos primeiros arquitetos, egresso da Escola Nacional de Belas Artes, no Rio de Janeiro, que tivera atuação preponderante em Campinas fora Mário de Camargo Penteado. Membro de proeminente família de Campinas, cidade onde nascera, em 1905, ele era filho de José Ferreira Penteado e de Alice de Camargo Penteado. Em meados dos anos 1920, Mário Penteado mudou-se de Campinas para se graduar no Rio, o que ocorreu em 1931. A obra de Mario Penteado só nos últimos tempos vem sendo estudada. A contribuição mais importante para o conhecimento de suas atividades advém da dissertação de mestrado de Silvia Amaral Palazzi Zakia, defendida no Mestrado em Urbanismo da Pontifícia Universidade Católica de Campinas, em 2004. Por meio desta dissertação foi possível descobrir que o acervo de Penteado havia sido doado por sua família ao Centro de Documentação do Curso de Arquitetura daquela universidade, permitindo, assim, sua análise e a descoberta da autoria de muitas obras vinculadas aos referentes do mission style e de suas conjugações com o neocolonial de fundo luso-brasileiro, em Campinas. Grande parcela dessas obras vinculadas ao mission style foi feita para bairros em expansão, nos anos 1930, como o Cambuí e o Guanabara. Em 1934, como aponta Zakia, Penteado construiu sua primeira obra dentro do repertório missioneiro, a residência Zelina Pontes Ferreira, à rua Conceição, 876 (ZAKIA, 2004). A casa, um sobrado para classe média, reproduz a planta típica das habitações daquele período, no Brasil, com 
grande segmentação e especialização funcional de seus espaços. Em termos de composição volumétrica, a residência também não se diferencia muito das congêneres construídas naqueles anos, entretanto, em termos de referências estilísticas, é clara a adoção consciente dos pressupostos missões: fachada movimentada com envasaduras dando a impressão de predomínio de cheios sobre vazios; uso de elementos de madeira torneada na conformação de janelas gradeadas, arcos para demarcação, tanto da entrada principal quanto para um garde-cochère, já que o carro havia se tornado parte do programa doméstico naqueles anos. Fora esta, foi possível identificar várias outras residências de alto e médio padrão projetadas por Penteado, em Campinas.

Entretanto, Penteado também projetou algumas edificações dentro do repertório luso-brasileiro e outras, dentro do mission style, que fugiram do programa habitacional. Nesta última linha, podem ser apontados seus projetos para a igreja matriz de Cosmópolis, de 1956, construída em cima de antigo templo feito pelo escritório de Ramos de Azevedo, nos anos 1910; a igreja matriz de Limeira, que ostenta a fusão dos estilemas luso-brasileiros com hispano-americanos; o projeto da sede social do Clube Jundiaiense, de 1940, e o Hotel da Companhia Paulista de Transportes, na cidade paulista de Tupã, interior do estado, riscado na década de 1940.

Mas a investigação sobre a produção missioneira em Campinas nos revelou que alguns outros arquitetos também trabalharam dentro deste repertório: o engenheiro Antônio Dias de Gouvêa e Lix da Cunha, que desde 1924 realizaram projetos em diversos bairros da cidade, ajudando a disseminar a solução de casa isolada no lote e a expandir a mancha urbana, com os bairros Bonfim, Guanabara, Castelo e Vila Nova. A atuação de Antonio Gouvêa e Lix da Cunha, em Campinas, foi objeto de investigação da arquiteta e urbanista Simone Montanhez, que, sob nossa orientação examinou cerca de 1000 processos de aprovação de construções, depositados no Arquivo Municipal de Campinas, e compilou as informações sobre o neocolonial e o missões riscados por esses sócios (MONTANHEZ, 2010). Não coincidentemente, esses dois projetistas se formaram nos Estados Unidos, em 1918, numa conceituada escola, de nome Rose Polytechnic Institute, no estado de Indiana e trabalharam em Campinas, associados, entre 1926 e 1936 (ATIQUE; MONTANHEZ, 2010).

Esses projetos e obras mostram um nível de concepção espacial elevado, pois traduzem, com grande requinte de detalhes, elementos e partidos arquitetônicos muito próximos daqueles realizados nos Estados Unidos, em outros países do continente americano e na então capital federal: o Rio de Janeiro. É impossível não apontar que o 
estilo missões saído das pranchetas de Penteado, Cunha e Gouvêa traz concepções arquitetônicas próximas aos dos catálogos e revistas encontrados em profusão pelo Brasil afora. O caso de Penteado, além, inscreve-se no estudo da produção dos egressos da ENBA. Neste sentido, por exemplo, deve-se mostrar que Frederico Faro Filho, que tendo se formado nos anos 1920 chegou a professor nos anos 1930, também foi titular de um escritório muito atuante no Rio de Janeiro, nas décadas de 1930 e 1940 cuja produção, em grande escala voltou-se ao missões. Encontraram-se muitas obras saídas de sua prancheta, em revistas brasileiras, como a revista oficial do Instituto de Arquitetos do Brasil - IAB - a Arquitetura e Urbanismo. Fora as residências a obra que mais o divulgou foi a igreja Nossa Senhora do Brasil, projetada em 1925 e concluída em 1934, no bairro carioca da Urca, celeiro de edificações missões. Talvez por conta da formação na mesma escola, a igreja matriz de Cosmópolis, de Mario Penteado, dos anos 1950, apresenta partido semelhante a esta congênere carioca, muito embora seja resolvida em um só plano, sem a necessidade de verticalização.

Outros arquitetos ligados à ENBA tiveram grande projeção social por conta das edificações neocoloniais, mas, sobretudo, missões que projetaram. Uma nota mais detida, contudo, deve ser feita para se falar de Ângelo Alberto Murgel. Em 1938 ele publicou alguns esboços de uma residência missões, na Arquitetura e Urbanismo, que mostra o emprego de soluções compositivas de maneira muito elegante (ARQUITETURA E URBANISMO, n.17, p.316 - 317). Aliás, Murgel teve uma prolífica atuação dentro dos referentes neocoloniais, sobretudo do mission style. De sua prancheta saíram edifícios imponentes como as sedes dos parques nacionais do Itatiaia, no Rio de Janeiro, e de Foz do Iguaçu, no Paraná. O aeroporto desta cidade turística paranaense também foi por ele projetado e executado, além do campus da atual Universidade Federal Rural do Rio de Janeiro, em Seropédica. Todos estes projetos datam das décadas de 1930 e 1940 e mostram o pleno conhecimento do arquiteto acerca da arquitetura utilizada em programas iguais, pelas Américas.

A Arquitetura e Urbanismo também mostrou muitas outras obras missões, sobretudo no Rio de Janeiro, como as residências projetadas para João Daudt de Oliveira e para Adelaide Daudt de Oliveira por Lucio Costa e Fernando Valentim, ${ }^{16}$

\footnotetext{
${ }^{16}$ A arquiteta Nora Geoffroy, em sua pesquisa de doutoramento, descobriu outros dois projetos dessa dupla a seguir os preceitos missioneiros: a residência Álvaro Alberto à rua Barata Ribeiro, de 1927, com área total edificada de quase $500 \mathrm{~m}^{2}$, e uma casa no Distrito da Glória, de 1926, cujo construtor foi Carlos Del Negro, professor da ENBA e projetista afinado com o mission style. A área construída desta casa era de $233 \mathrm{~m}^{2}$ (GEOFFROY, 2004, p.233-236).
} 
publicadas na edição de número 16, do bimestre setembro - outubro de 1938. As casas, vizinhas, ocupam grande gleba e, apesar de terem plantas estruturadas segundo as regras compositivas do "morar à francesa", são bons exemplos da arquitetura missioneira. Intermediando as duas residências, bem ao fundo de um eixo principal, os arquitetos, sócios à época, colocaram uma fonte explicitando as referências ao estilo missões, empregadas em todo o projeto (ARQUITETURA E URBANISMO, 1938, n.16, p.238250). Valendo-se de telhados sem beiral algum, de arcos mudejares, de toldos listrados os quais, a partir da efetiva introdução de referências mediterrâneas ao escopo de elementos missões, nos Estados Unidos, também se propagaram como mais uma de suas características -, as duas residências mostram que Lucio Costa, adepto do neocolonial na década de 1920, e arquiteto que se referenciaria à arquitetura colonial brasileira em muitas obras futuras, também soube projetar dentro dos princípios compositivos do mission style, algo que negaria depois de sua auto-propalada conversão ao ideário moderno.

Até aqui se falou da importância das revistas americanas na formação de repertório das instituições de ensino superior, sobretudo em arquitetura, no país. Comentou-se a importância das revistas ligadas ao universo específico de ação de arquitetos e de engenheiros, mas é preciso abrir espaço para comentar as revistas que, mais do que serem dirigidas para os profissionais diplomados, geraram clientes nos estratos médios da sociedade, alimentando o anseio pela casa própria (NASCIMENTO, 2004, p.19). Neste grupo, a pesquisa encontrou fortes e surpreendentes referências. A mais importante, sem dúvida, foi a revista A Casa.

Criada pelo arquiteto Ricardo Wriedt, em 1923, A Casa, logo em 1924, se tornou propriedade de Segadas \& Cordeiro, empresa formada pelo engenheiro civil A. Segadas Vianna e pelo arquiteto J. Cordeiro de Azeredo. Como explicava seu subtítulo, a revista era destinada a engenheiros, arquitetos, artistas e decoradores, com periodicidade mensal e com tiragens que, em princípio, eram de 4 mil exemplares, mas que, em 1940, já haviam alcançado a casa das 8 mil cópias. Publicado no Rio de Janeiro, o periódico que articulava o cenário arquitetônico local para buscar colaboradores, logo passou a receber contribuições, via correio, de diversos estados, e chegou a abrir representação própria em São Paulo. Por isso, em seus números, era possível encontrar projetos de expoentes da arquitetura nacional e de anônimos, que expunham suas concepções 
arquitetônicas. É importante mostrar como A Casa se prestou à divulgação das referências estético-arquitetônicas provenientes dos Estados Unidos e da América Latina. Reportagens sobre energia elétrica, equipamentos domésticos e técnicas construtivas eram pauta frequente, mas, sem dúvida nenhuma, eram os projetos de habitações ligadas ao missões que abundavam em suas páginas.

Não tardou e a revista passou a organizar concursos destinados a obter projetos para casas suburbanas e rurais. Estes concursos recebiam o apoio de pessoas ou empresas patrocinadoras que doavam dinheiro para premiar os ganhadores. $\mathrm{O}$ primeiro concurso, ocorrido em 1925, teve como vencedores os arquitetos J. de Souza Camargo, junto com seu colega Carlos Rapozo, que já eram colaboradores habituais da publicação. Na segunda edição da disputa, o primeiro lugar foi obtido pelo mesmo J. de Souza Camargo, seguido, em segunda posição, por A. de Simonin Mattos e Carlos do Rego Raposo. Os concursos estipulavam a necessidade de adoção de um estilo que conviesse ao meio rural ou suburbano e que, além disso, possuísse um orçamento competitivo, a ser entregue nas mesmas pranchas do projeto arquitetônico, como principal elemento do julgamento. As propostas deveriam seguir as normas edilícias da prefeitura do então Distrito Federal. Os concursos eram muito disputados e forneciam matérias para A Casa, por meses, já que, mesmo após o julgamento, as proposições consideradas pelos editores como contribuição ao tema eram publicadas.

É muito importante dizer que os projetos de habitação de caráter popular se tornaram o carro-chefe da publicação, o que favorecia a ampliação do número de leitores, não só, via assinaturas, mas também pela aquisição em bancas. A temática desses concursos estava na ordem do dia nos anos 1920, sendo algo que já havia sido discutido, algumas vezes, nos Congressos Pan-Americanos de Arquitetos (ATIQUE, 2009). Também não se pode furtar de dizer que a adoção de um neocolonial simplificado, usando a expressão cunhada por Carlos Lemos, e, sobretudo, o uso do estilo missões aproximavam os projetos de habitação proletária feito nas demais Repúblicas sul-americanas, desses do Brasil.

\section{O “Mission Style” como "Arquitetura Pan-Americana"}

É importante mostrar que os processos arquitetônicos verificados no Brasil foram semelhantes aos de muitos outros países americanos. As referências da arquitetura missões foram empregadas tanto nos Estados Unidos, como em lugares 
como Cuba, Colômbia, Argentina, Chile, Venezuela e Bolívia, entre outros, seguindo os mesmos caminhos mostrados no caso brasileiro. Mesmo que, por vezes, se chame de arquitetura hispano-americana ao mission style, percebeu-se que os países de colonização espanhola, além de buscarem encontrar suas referências arquitetônicas nos edifícios coloniais de seus próprios territórios, como ocorreu no Brasil, também se valeram das revistas, manuais e álbuns emanados dos Estados Unidos na produção de seus neocoloniais.

A leitura sistêmica da produção arquitetônica do continente americano é tarefa árdua e demorada, mas foi um desafio a ser enfrentado, permitindo afirmar que houve, durante muitas décadas, entre fins do século XIX e a primeira metade do século XX, diálogos entre o Brasil e os demais países americanos, fossem eles de fala espanhola ou inglesa. Esses diálogos velados têm sido notados por poucos pesquisadores ligados à história urbana e, em menor número, por interessados na história da arquitetura. Ao escolher o mission style como mote discursivo desse contato, intentou-se colaborar com essa área de estudos que ainda merece maior atenção neste campo, a despeito, de uma consolidada e efervescente produção historiográfica no campo das representações pictóricas, da música e das ideias políticas da América.

Algumas semelhanças verificadas nos processos de recepção e desenvolvimento do mission style nos países americanos devem ser apontadas à guisa de considerações finais. Parece ser importante mostrar que os interesses econômicos dos Estados Unidos espalhados por muitos países de ascendência hispânica permitiram a construção de arquiteturas missões, diretamente por arquitetos e empresas americanas. Como mostram Francisco Ramirez Potes, Jaime Gutiérrez Paz e Rodrigo Uribe Arboleda, no livro Arquitecturas Neocoloniales: Cali 1920 - 1950, sabe-se que a firma nova-iorquina de Fred Ley \& Co. desenhou edifícios na Colômbia, no Equador, no Peru e no Chile, via de regra, empregando a arquitetura missões, julgada como adequada a países ligados à Espanha, no passado. Outro americano a trabalhar na América do Sul foi Geo Bunker que, para Cali, projetou reservatórios de água dentro da temática missões. No mesmo país, outro escritório nova-iorquino, o de Clifford C. Wendehack realizou algumas residências e, em Caracas, na Venezuela, essa firma projetou e executou o "Caracas Country Club" (POTES, 2000, p.34). Uma empresa urbanizadora, de nome Foundation Co., atuante em Lima, nos anos 1930, não apenas divulgou o modelo de subúrbio habitacional, como nele implantou os primeiros chalets californianos. Como mostra Potes, o modelo habitacional derivado da Califórnia e também da Flórida foi produzido 
em Barranquilla, Colômbia, no bairro El Prado, pelo arquiteto americano Karl Parrisch, que trabalhou ao lado do paisagista estadunidense Roy F. Wyrick (POTES, 2000, p.35).

No México, a construção de Rosita, indústria adquirida pela American Smelting \& Refining Co. da Compañia Carbonífera de Sabinas, nos anos 1910, e transformada em company town, em 1921, mostra outra faceta dos arquitetos estadunidenses nos demais países americanos. Pelo projeto do arquiteto Hjalmar E. Skougor, de Nova York, que projetou 208 casas para operários, teatro, hospital, escola, mercado, galpões industriais e muitas dezenas de casas para chefes e administradores, os referentes missioneiros, algumas vezes conjugados aos estilemas do Pueblo Style, passaram a ser vistos como um bom modelo para outras empreitadas fabris dos americanos. Para exata compreensão deve-se ter em mente não só a dimensão do projeto, mas, ainda, o fato de ele ter sido publicado em 1921, na revista Coal Age, destinada a empresários do setor (COAL AGE, 1921, p.983 - 1040). A repercussão desses núcleos fabris dentro da arquitetura missioneira foi mostrada por Telma de Barros Correia, em núcleos fabris destinados à extração de nitrato, no norte do Chile, por empresas norte-americanas, as quais se valeram, também, de edificações missões. Entre eles, a autora aponta, está a Oficina Maria Elena, de 1925 (CORREIA, 1995, p.117). No Panamá, a Compañia del Canal del Panamá construiu, em 1915, um bloco de apartamentos para solteiros, dentro dos estilemas neocoloniais (AMARAL, 1994, p.303).

Igrejas, como a episcopal de Santíssima Trinidad, de 1905, já demolida, foi riscada pelo arquiteto americano Bertram G. Goodhue, em Cuba. A ilha, que depois da Guerra de 1898 se tornou um dos principais locais de ação americana, recebeu inúmeras edificações semelhantes às encontradas na Califórnia e na Flórida. Como exemplo, citase a estação central de trens de Havana, projetada e construída por Kenneth Murchison, entre 1910 e 1912 (CODY, 2003, p.24). Jefrrey Cody aponta que, fora Goodhue e Murchison, atuaram ativamente, em Cuba, os escritórios de arquitetura de Barclay, Parsons and Klapp e o de Carrere and Hastings, além da construtora Purdy \& Henderson (CODY, 2003, p.24). Este mesmo autor mostra que o projeto do Bank Boston de Buenos Aires, na Argentina, de 1921 - 1924, foi feito por Paul Bell Chambers, educado na Grã-Bretanha, e por Louis Newberry Thomas, nativo, mas que fora educado no Brooklyn's Pratt Institute, ao lado de dois outros escritórios (Edward Tork \& Philip Sawyer e Stone \& Webster) que haviam acabado de inaugurar a sede da instituição bancária, em Boston. O projeto foi concebido dentro da incorporação dos estilemas missioneiros, com direito a suntuosa portada barroca sobre uma estrutura 
metálica, em franca difusão nos Estados Unidos, naquele momento (CODY, 2003, p.64 $-65)$.

Aliás, estas informações de Cody abrem espaço para comentar a ação de arquitetos nativos ou fixados no Brasil que produziram arquiteturas seguindo os princípios norte-americanos. Convém recapitular que o pavilhão dos Estados Unidos, construído por ocasião da Exposição Internacional do Centenário, ocorrida entre 1922 e 1923, foi feito pelo arquiteto Frank Packard, que se valeu de muitas características do neocolonial de fundo luso-brasileiro, mas que, sem dúvida, incorporou muitos referentes missioneiros, sobretudo na conformação do pátio central da obra, que serviu, por algum tempo, como sede da Embaixada dos Estados Unidos, no Brasil (ATIQUE, 2011).

Como apontaram Potes e equipe, o desenvolvimento da arquitetura neocolonial no continente americano fez necessária a investigação aprofundada das arquiteturas do passado, por meio da emergência da figura do arquiteto-historiador. Para eles, da Argentina ao México, pode-se falar de uma geração que teve os mesmos interesses, como Angel Guido, Martín Noel e Mario Buschiazzo, na Argentina; Roberto Dávila Carson, no Chile; Emílio Harth-Terré e Héctor Velarde, no Peru e Frederico Mariscal, no México (POTES, 2000, p.43). Os autores, entretanto, excluem o Brasil e os Estados Unidos desta lista, a despeito das contribuições desses países. A importância desses levantamentos foi capital para muitos arquitetos e críticos ligados à difusão do neocolonial no continente americano, e mostra a eclosão de um movimento panamericano, de fato, ligado à publicação dos espaços e dos elementos arquitetônicos, ampliando a circulação de imagens e projetos entre as Américas. No Brasil, por exemplo, como sugere Carlos Kessel, Ricardo Severo contratou os serviços de José Wasth Rodrigues para representar as edificações, ornamentos, arremates, ferragens e demais elementos constitutivos da arquitetura colonial, para a publicação de um Dicionário sobre a Arte e a Arquitetura Colonial do Brasil, obra nunca saída do prelo, mas que pode ser vislumbrada, em certa medida, no livro que Rodrigues publicou, décadas depois, sob o nome de Documentário Arquitetônico Relativo à Antiga Construção Civil no Brasil (KESSEL, 2008; RODRIGUES, 1979). José Marianno, por sua vez, comissionou as famosas viagens de estudo da Arquitetura Tradicional do Brasil, em 1924, da qual fizeram parte Lucio Costa, Nestor Emgydeo de Figueiredo e Nereo Sampaio. É impossível não comparar a iniciativa dessas viagens saídas do Rio de Janeiro e de São Paulo, pela mão de Alexandre Albuquerque, visando a constituição desses "álbuns", com as publicações de Rexford Newcomb e de Richard W. Sexton, 
americanos que depois de visitas de levantamento a lugarejos nos estados do Novo México, Califórnia e Texas, publicaram manuais de divulgação da arquitetura hispânica, os quais se tornaram referências obrigatórias para o entendimento da arquitetura colonial nos territórios, hoje, ocupados pelos Estados Unidos (NEWCOMB, 1916). É interessante não esquecer da viagem de Albert Kelsey ao México durante a feitura do projeto do Pan-American Union Building, em Washington, em 1907.

No universo hispano-americano, deve-se apontar, também, a contribuição de Mario J. Buschiazzo que fez publicar, nos mesmos moldes dos seus colegas brasileiros e norte-americanos, seus Estudios de Arquitectura Colonial Hispano Americana, em Buenos Aires, em 1944.

Ainda dentro da discussão da divulgação da arquitetura por meio de publicações, deve-se falar da circulação, no contexto pan-americano, das revistas como Architectural Digest, American Architect, Arts and Decoration, House and Garden, Landscape Architecture, California Arts and Architecture, que foram importantes referências para a chegada do mission style ao Brasil, mas que também foram cruciais em outros países. Potes e equipe afirmam que o conhecimento dos projetos publicados nessas revistas, pelos latinos, ajudou a cristalizar algo que já foi indicado nesta obra: a atenção dada à arquitetura americana. Esta mesma equipe de pesquisadores ajuda a elencar os arquitetos leitores dessas publicações estadunidenses: na Argentina, Alejandro Christophersen recomendava a leitura da revista The Architect, onde "havia encontrado tipos de casas de campo e de estâncias perfeitamente adaptáveis à Argentina”; sua atitude era amplificada, entretanto, por seu colega Raúl J. Alvarez que dizia, explicitamente, da necessidade de tomar os exemplos dos norte-americanos que têm sabido erigir sobre toda a Califórnia uma arquitetura regional, a qual deveria ser “transplantada” para seu país. No Uruguai, por meio da Revista Ultra, Raúl Llerena Acevedo recomendava a adoção do "Colonial Californiano" (POTES, 2000, p.34). No Brasil, apesar de mais reticente ao neocolonial, Christiano das Neves também afirmava, por meio da Revista de Engenharia do Mackenzie College que o Spanish Renaissance" era "o estylo que devíamos cultivar por ser realmente agradavel e adaptavel ao nosso clima e á nossa natureza" (NEVES, 1919, p.41).

Todo este entusiasmo pelo mission style alcançou não apenas os profissionais de formação erudita nas academias, como os nomes acima citados permitem ver, mas, principalmente, clientes. Entre estes, algo que não pode deixar de ser citado é a recomendação de Eva Perón, na Argentina, para que as casas construídas durante o 
governo populista de Perón fossem adeptas do mission style, que demonstraria "a apropriação simbólica", por parte de grandes setores populares, de um dos "principais atributos físicos de conforto e de dignidade" exibidos, até aquele momento, apenas em edifícios destinados às altas e médias camadas da população (PETRINA, 1994, p.291). A sugestão de "Evita" parece ter sido a oficialização de um processo, como mostra Ramon Gutierrez:

\footnotetext{
“Se moldou, assim, a mítica imagem do 'chalet californiano' como símbolo de status, de prestigio, e como modelo. Inicialmente, foi utilizado pelas classes altas, em suas variantes pitorescas; o consolidaram logo as classes médias, nos subúrbios das grandes cidades, em especial Buenos Aires, Córdoba, Rosário e La Plata, e, insistentemente, os setores populares o requisitavam para as habitações que o Governo planejava" [tradução minha] (GUTIERREZ, citado por POTES, 2000, p.35).
}

No Brasil viu-se, também, a importância da revista A Casa na disseminação de habitações das classes médias urbanas. Por essas similaridades não apenas estéticoconstrutivas, mas, sobretudo, de método divulgador, é que se pode afirmar que o mission style foi uma arquitetura pan-americana, encontrada do norte do continente americano à Terra do Fogo. Esquecido ou mal-compreendido, por décadas, espera-se que por meio da leitura empreendida, neste artigo, a maneira de vislumbrar essa arquitetura ajude a redefinir algumas abordagens no trato das relações do Brasil com os Estados Unidos, e do Brasil com os demais países americanos por meio da construção do espaço.

\section{Referências Bibliográficas}

A EXPOSIÇÃO do Centenario. Architectura no Brasil. Rio de Janeiro: n.24, v.4, a. II, set, 1923, p. 143-154.

A NOITE. Editorial. 14 jul 1927, p.1.

ADAMS, Charles Gibbs. The window grilles of Old Mexico. California: arts and architecture. Los Angeles: p. 17 - 18, Feb - Mar, 1933.

AMARAL, Aracy. Arquitectura neocolonial: América Latina, Caribe, Estados Unidos. São Paulo: Fondo de Cultura Econômica / Memorial da América Latina, 1994.

ANTE-projeto de uma residência a Av. Epitácio Pessoa, de Carlos Porto \& Caio Moacyr Ltd. Revista de Arquitetura da ENBA. Rio de Janeiro: ENBA, n.13, jul, 1935, p.12-13. 
APPLETON, Marc. Introduction. In: NEWCOMB, Rexford. Mediterranean domestic architecture in the United States. New York: Acanthus Press, 1999.

ARCHITECTURAL RECORD. Rexford Newcomb. Architectural Record. New York: v. 144, n.9, p.36-36, Sep, 1968.

ARQUITECTOS Lucio Costa e F. Valentim. Arquitetura e Urbanismo. Rio de Janeiro: IAB, n. 16, set - out, 1938, p.238 - 250.

ARQUITETURA E URBANISMO. Rio de Janeiro: Instituto de Arquitetos do Brasil, 1940, a. $\mathrm{V}$, mar-abr.

AS RESIDENCIAS do Dr. João Daudt de Oliveira e Ex. senhora D. Adelaide Daudt de Oliveira. Arquitetos Lucio Costa e F. Valentim. Arquitetura e Urbanismo. Rio de Janeiro: IAB, n. 16, set-out, 1938, p.238-250.

ATIQUE, Fernando. Celebrando (com) Tio Sam: o Centenário da Independência do Brasil e os Estados Unidos. Pterodáctilo. University of Texas at Austin, n.10, spring, 2011. Disponível em: http://pterodactilo.com/numero10/?p=2516

ATIQUE, Fernando. Arquitetando a "Boa Vizinhança": arquitetura, cidade e cultura nas relações Brasil-Estados Unidos, 1876-1945. Campinas: Pontes / FAPESP, 2010.

Estantes em inglês: levantamento e discussão de algumas obras de procedência norteamericana, presentes em instituições de ensino de São Paulo e do Rio de Janeiro, formadoras de engenheiros e arquitetos, na primeira metade do século XX. (Terceiro Trabalho Programado apresentado ao Programa de Pós-Graduação em Arquitetura e Urbanismo da FAU-USP). São Paulo: 2005.

; MONTANHEZ, Simone. The "Gouvêa e Cunha" Office: an important place for the construction of Modern Campinas. Paper apresentado na $14^{\text {th }}$ International Planning History Soceity Conference. Istambul, 2010.

AUSTIN, E. L.; HAUSER, Odell. The Sesqui-Centennial International Exposition: a record based on Official Data and Departmental Reports. Philadelphia: Current Publications, 1929.

AZEVEDO, Ricardo Marques de. Las ideas de Ricardo Severo y la relación con el academicismo. In: AMARAL, Aracy. Arquitectura neocolonial: América Latina, Caribe, Estados Unidos. São Paulo: Fondo de Cultura Económica / Memorial da América Latina, 1994.

BAER, Kurt. Architecture of the California missions. Berkeley: University of California Press, 1958.

BARRET, John. The Pan American Union: peace, friendship, commerce. Washington: Pan American Union, 1911. 
BERTZ; WINTER: MAURY. R. Max Cohn's country home situated in the Los gatos Hills. California: arts and architecture. Los Angeles: p. 22 - 24, Feb, 1930.

BONDUKI, Nabil. Origens da habitação social no Brasil: arquitetura moderna, lei do inquilinato e difusão da casa própria. São Paulo: Estação Liberdade, 1999.

BOSSOM, Alfred C. An architectural Pilgrimage in old Mexico. New York: Charles Scribner's sons, 1924.

BRATKE, Oswaldo Arthur; BOTTI, Carlos. Residencia Manoel Vega, rua Chile, 17-b. Acrópole. São Paulo: n.3, p. 57 - 61, jul, 1938.

BUNGALOW hespanhol. Projecto de Moacyr Fraga, alumno da ENBA. Architectura: mensário de arte. Rio de Janeiro: a. I, n.3, ago, 1929, p.36-37.

BUNGALOW missões. Luiz Gilleo, architecto. Architectura: mensário de arte. Rio de Janeiro: a. II, n.12, mai, 1930, p.24.

BUSCHIAZZO, Mario José. Estudios de arquitectura colonial hispano americana. Buenos Aires: G. Kraft, 1944

CAIUBY, Olavo Franco. Residencia Quirino Gastão de Sá, r. Venezuela, 202. Acrópole. São Paulo: n.18, p. 33 - 37, out, 1939.

CALIFORNIA Houses. Architectural record. S.n., p. 318 - 340, Oct, 1922.

CARVALHO, Maria Cristina Wolff de. Ramos de Azevedo. São Paulo: EDUSP, 1999.

A arquitetura de Francisco de Paula Ramos de Azevedo. In: Cidade: revista do Departamento do Patrimônio Histórico. São Paulo: Secretaria Municipal de Cultura de São Paulo, a.V, n.5, jan, 1998. p. 4-19.

CARVAlHO, Roberto Magno de. Hotel Balneário. Revista Politécnica. São Paulo: Escola Politécnica, n.134, p.33 - 36, abr - mai, 1940.

CASA para renda. Arquiteto Roberto Magno de Carvalho. Arquitetura e Urbanismo. Rio de Janeiro: IAB, mai - jun, 1939, p.515 - 516.

CASA rua fonte da saudade, 329. Arquiteto Miguel Barroso do Amaral. Arquitetura $e$ Urbanismo. Rio de Janeiro: IAB, n.13, mar - abr, 1938, p.74-75.

CASAS econômicas. Architectos J. de Souza Camargo e Ângelo Brhuns. A Casa. Rio de Janeiro: n.14, jun, 1925, p.26.

CHANDLER, Joseph Everett. The colonial house. New York: McBride, 1916, [1924].

CHURCH, Thomas D. Peasant courtyards of Spain - patios that are useful, simple, and still charming. California: arts and architecture. Los Angeles: p. 19 - 21, Feb, 1930. 
CODY, Jeffrey W. Exporting American architecture: 1870 - 2000. New York: Routledge, 2003.

COLONIAL HESPANHOL. Croquis de Moacyr Fraga. Architectura: mensário de arte. Rio de Janeiro: a. I, n.2, jul, 1929, p.23-25.

COLONIAL mouro-missões. Residencia do narrador arabe Malba Tahan. Architectura: mensário de arte. Rio de Janeiro: a. I, n.3, ago, 1929, p.24-25.

CONCURSO da A Casa. A Casa. Rio de Janeiro: n.14, jun, 1925, p.5. (edital).

CONCURSO da A Casa. A Casa. Rio de Janeiro: n.18, out, 1925, p.18-19.

CONCURSO de 'A Casa'. Projeto de Ricardo Wriedt e J. Cordeiro de Azeredo. A Casa. Rio de Janeiro: n.23, a. IV, mar., 1926, p.12-13.

CONCURSOS de projectos de casas econômicas. A Casa. Rio de Janeiro: n.98, a. X, jul., 1932, p.10-12.

CONCURSOS de projectos de casas econômicas. A Casa. Rio de Janeiro: n.98, a. X, jul., 1932, p.22-24.

CORREIA, Telma de Barros. Pedra: plano e cotidiano operário no sertão. Campinas: Papirus, 1998.

COSTA, Angyone. A inquietação das abelhas: inquérito sobre a vida artística brasileira. Rio de Janeiro: Pimenta de Mello e Cia., 1927.

CUNHA FILHO, José Marianno Carneiro da. Educação Urbanística do Povo. Diário de Notícias. Rio de Janeiro, 14 mar, 1931, s.p.

. Right or wrong, it is my house. O Jornal. Rio de Janeiro, ? jul, 1931, s.p.

. As características do estilo arquitetônico nacional. O Jornal. Rio de Janeiro, 8, jul, 1931,

. Palavras vans. O Jornal. Rio de Janeiro, 26, jan, 1930, s.p.

Definindo mais uma vez meu pensamento. In: Architectura: mensário de arte. Rio de Janeiro: a.I, n.7, dez, 1929. p. 9 -10. s.p.

DUAS RESIDENCIAS em estylo 'missões hespanholas' á rua Mauá, n. 62 e 64 - Santa Theresa. Edgar P. Vianna, architecto. Architectura no Brasil. Rio de Janeiro: n.25, v.5, a. III, nov, 1925, p.16-18, p.23, separata de desenhos.

DUNLOP, J.B. Rio Antigo. $2^{\mathrm{a}}$ ed. Rio de Janeiro: Editora Rio Antigo, 1958, 3v.

EBERLEIN, Harold Donaldson. Spanish interiors, furniture and details, from the $14^{\text {th }}$ to $17^{\text {th }}$ century. New York: Architectural Book, 1925. 
EDGAR P. VIANNA, architecto. Architectura no Brasil. Rio de Janeiro: n.27, v.5, fev-mar, 1926, p.III. (cartão que participa a abertura de seu escritório).

ESBOÇO de Ângelo Murgel, arquiteto. Arquitetura e Urbanismo. Rio de Janeiro: IAB, n.17, nov - dez, 1938, p.316 - 317.

ESTYLO Californiano. A Casa. Rio de Janeiro: n.98, a. X, jul., 1932, p.27.

ESTYLO Missões Hespanholas, architecto Raphael Galvão. A Casa. Rio de Janeiro: n.39, a. V, jul., 1927, p.17.

GEOFFROY, Nora Maria Mendes Guimarães. A morada carioca no contexto das zonas norte e sul nos anos 20. (Dissertação de mestrado). São Paulo: Faculdade de Arquitetura e Urbanismo, Universidade de São Paulo, 2004.

GIBSON, Thomas; MACK, Gerstle. Architectural details of Southern Spain: one hundred measured drawings, one hundred and thirteen photographs. New York: W. Helburn, 1928.

GROSSMAN, Elizabeth Greenwell. The civic architecture of Paul Cret. New York: Cambridge University Press, 1996.

HARBESON, Paul. Winning designs: 1904 - 1927, Paris prize in architecture. New York: Pencil Points, 1928.

The Study of Architectural Design, with Special Reference to the Program of the BeauxArts institute of Design. Nova York: Pencil Points, 1927.

HARRINGTON, John. Spanish heritage. California: arts and architecture. Los Angeles: p. 16 17, Feb, 1939.

HAWTHORNE, Nathaniel. Our old home. Boston: Houghton, 1907.

IGREJA na Urca. Arquiteto F. Faro Filho. Arquitetura e Urbanismo. Rio de Janeiro: IAB, maijun, 1936, p. 37.

IRIGOYEN DE TOUCEDA, Adriana Marta. Da Califórnia a São Paulo: refêrencias norteamericanas na casa moderna paulista, 1945-1960. São Paulo: Faculdade de Arquitetura e Urbanismo, Universidade de São Paulo, 2005.

JOHNSTON, Reginald D. J.P. Jefferson house, Montecito. Architectural record. S.n., p. 8- 15, Jan, 1922.

KELSEY, Albert. Yucatecan scenes and sounds. Philadelphia: the Numismatic Society of Philadelphia, 1919.

KESSEL, Carlos. Arquitetura neocolonial no Brasil: entre o pastiche e a modernidade. Rio de Janeiro, Jauá, 2008. 
LEMOS, Carlos A. C. Alvenaria burguesa: breve história da arquitetura residencial de tijolos em São Paulo a partir do ciclo econômico liderado pelo café. $2^{a}$ ed. São Paulo: Nobel, 1989.

MONTANHEZ, Simone. A atuação profissional de Lix da Cunha em Campinas (1924-1936). (Relatório de Iniciação Científica FAPESP). Itatiba: Universidade São Francisco, 2010.

MORALES DE LOS RIOS, Adolfo. Tese apresentada no Concurso para o lugar de Lente de Estereotomia da Escola Nacional de Belas Artes. Rio de Janeiro, 1897.

LOS RIOS FILHO, Adolfo Morales de. Arquitetura não é Standard. Revista de Arquitetura da ENBA. Rio de Janeiro: ENBA, n.9, mar, 1935, p.11.

NASCIMENTO, Flávia Brito do. Entre a estética e o hábito: o Departamento da Habitação Popular - Rio de Janeiro, 1946-1960. (Dissertação de mestrado). São Carlos: Escola de Engenharia de São Carlos, Universidade de São Paulo, 2004.

NASLAVSKY, Guilah. Modernidade arquitetônica no Recife: arte, técnica e arquitetura de 1920 a 1950. (Dissertação de mestrado). São Paulo: Faculdade de Arquitetura e Urbanismo, Universidade de São Paulo, 1998.

NEVES, Christiano Stockler das. Architectura Colonial. In: Revista de Engenharia do Mackenzie College, n.19, jul, 1919.

NEWCOMB, Rexford. The Franciscan mission architecture of Alta California. New York: Dover Publications, 1916.

. Spanish-Colonial Architecture in the United States. New York: J.J. Augustin, s.d.

.The Mediterranean Domestic Architecture in the United States. Cleveland: Janson, 1928.

. The Spanish house for America: its design, furnishing and garden. Philadelphia: J.B. Lippincott, 1927.

PEQUENA residencia typo 'colonial hespanhol'. Projecto de Moacyr Fraga. Architectura: mensário de arte. Rio de Janeiro: a. I, n.1, 8 jun., 1929, p.16. (o mesmo projeto figura na capa desse número).

PEREIRA, Gustavo. Christiano Stockler das Neves e a formação do curso de arquitetura no Mackenzie College: um estudo sobre as École de Beaux-Arts e as Fine Arts Schools norteamericanas. (Dissertação de mestrado). São Paulo: Universidade Presbiteriana Mackenzie, 2005.

PERSPECTIVA do ante-projecto para o pavilhão do Brasil na exposição de Philadelphia. Rapahel Galvão e Edgar Vianna, architectos. Architectura no Brasil. Rio de Janeiro, n.28, v.5, abr-mai, 1926. (capa da edição). 
PETRINA, Alberto. Tránsito de la arquitectura hispanocriolla: de la vitalidad nacional a la banalidad comercial. In: AMARAL, Aracy. Arquitectura neocolonial: América Latina, Caribe, Estados Unidos. São Paulo: Fondo de Cultura Económica; Memorial da América Latina, 1994. POTES, Francisco Ramírez; PAZ, Jaime Gutiérrez; ARBOLEDA, Rodrigo Uribe. Arquitecturas neocoloniales: Cali, 1920 - 1950. Cali: Centro de Investigaciones em Territorio, Construcción y Espacio, Universidade del Valle, 2000.

PROJECTO de casa economica. A Casa. Rio de Janeiro: n.18, out, 1925, p.17. (projeto de Emerson Fernandes).

PROJECTO DE HABITAÇÃO em Jacarepaguá, propriedade do Snr. Dr. José Marianno Filho. A Casa. Rio de Janeiro: n.40, a. V, ago., 1927, p.25.

PROJECTO de habitação em Jacarepaguá, propriedade do snr. José Marianno Filho. A Casa. Rio de Janeiro: n.39, a. V, jul., 1927, p.21.

PROJECTO de habitação rural, Cortez e Bruhns. A Casa. Rio de Janeiro: n.24, a. IV, abr., 1926, p.9.

PROJECTO de habitação suburbana, Cortez e Bruhns. A Casa. Rio de Janeiro: n.24, a. IV, abr., 1926, p.10

PROJECTO de habitação suburbana, de Cortez e Bruhns. A Casa. Rio de Janeiro: n.27, a. IV, jul., 1926, p.12.

PROJECTO de Robert Kissel. A Casa. Rio de Janeiro: n.42, a. V, out., 1927, p.37.

PROJECTO de uma residência no Leblon. A Casa. Rio de Janeiro: n.26, a. IV, jun., 1926, p.13.

PROJECTO em estylo colonial mexicano, architecto Moacyr fraga. A Casa. Rio de Janeiro: n.41, a. V, set., 1927, p.25.

PROJECTO em estylo colonial mexicano. A Casa. Rio de Janeiro: n.42, a. V, out., 1927, p.21.

PROJECTO para o banco do Rio de Janeiro. Edgar P. Vianna, architecto. Architectura no Brasil. Rio de Janeiro, n.23, v.4, a. II, ago, 1923, p. 129, 131 e 133.

PROJECTOS de Moacyr Fraga, typo XIV e typo V. A Casa. Rio de Janeiro: n.42, a. V, out., 1927, p. 30-31.

PROJETO de Galo, Barata e Fonseca. Revista de Arquitetura da ENBA. Rio de Janeiro: ENBA, n.13, jul, 1935, p.22.

PROPRIEDADE da Exm. Dr. Rivadavia Correa Meyer. Arquiteto Raphael Galvão. Arquitetura e Urbanismo. Rio de Janeiro: IAB, n.9, jul - ago, 1937, p.184 - 185. 
PROPRIEDADE do Ex. Sr. João Daltro Filho. Arquiteto F. Faro Filho. Arquitetura $e$ Urbanismo. Rio de Janeiro: IAB, mai-jun, 1937, p. 117-130.

REED, Henry A. Topographical drawing and sketching, including applications of photography. New York: John Willey \& Sons, 1897 [1902].

REQUA, Richard S. Architectural Details, Spain and the Mediterranean. A portfolio of one hundred and forty-four plates; reproductions of photograhs taken, selected and arranged specially for use in developing a logical and appropriate style of architecture for California and the Pacific Southwest. Los Angeles: The Monolith Portland Cement Company, 1926.

Old World Inspiration for American Architecture. Los Angeles: The Monolith Portland Cement Company, 1929.

RESIDENCIA a ser construida no Leblon. Projeto de Galo-Barata \& Fonseca Lrda. Revista de Arquitetura da ENBA. Rio de Janeiro: ENBA, n.11, mai, 1935, p.10-11.

RESIDENCIA missões. Florida - Estados Unidos. Architectura: mensário de arte. Rio de Janeiro: a. I, n.2, jul, 1929, s/p. (separata da revista).

RESIDENCIA neocolonial. Architectura no Brasil. Rio de Janeiro: n.7-8, v.2, a. I, abrmai,1922. separata colorida da revista.

RESIDENCIA nos fundos de um terreno. Arquiteto R. M. Carvalho. Arquitetura e Urbanismo. Rio de Janeiro: IAB, jul - ago, 1939, p.590 - 591.

RESIDENCIA pitoresca. Arquiteto Eduardo Souto de Oliveira. Arquitetura e Urbanismo. Rio de Janeiro: IAB, n.234, jul - ago, 1939, p.570-571.

ROSITA. Coal Age. New York: McGraw-Hill, v.24, Jan, 1921, p. 983 - 1040.

ROUSIERS, Paul. La vie américaine. Paris: Firmin-Didot, 1892.

SÁ, Marcos Moraes de. A mansão Figner: o ecletismo e a casa burguesa no início do século XX. Rio de Janeiro: Editora SENAC, 2002.

SAGARENA, ROBERTO LINT. Building California's past: mission revival architecture and regional identity. In: Journal of Urban History, v. 28, n. 4, May, 2002: 429 - 444.

SANTOS, Maria Cecília Loschiavo dos. Escola Politécnica da Universidade de São Paulo: 1894 - 1984. São Paulo: Reitoria/Escola Politecnica/fdte, 1985.

SANTOS, Paulo. Quatro séculos de arquitetura. Rio de Janeiro: IAB, 1981.

SEGUNDO grande concurso da 'A CASA'. A Casa. Rio de Janeiro: n.21, a. IV, jan, 1926, p.5.

SEGUNDO grande concurso da 'A CASA'. A Casa. Rio de Janeiro: n.21, a. IV, jan, 1926, p.1320. 
SEGUNDO Grande concurso da 'A CASA'. Projeto de Habitação rural, Cortez e Brhuns. A Casa. Rio de Janeiro: n.21, a. IV, jan, 1926. p.13-15.

SEGUNDO grande concurso da 'A CASA'. Zona rural, primeiro prêmio. A Casa. Rio de Janeiro: n.21, a. IV, jan, 1926. (separata).

SEVERO, Ricardo. Da arquitetura colonial no Brasil: arqueologia e arte. In: O Estado de São Paulo, São Paulo, 7 set 1922.

A arte tradicional do Brasil: a casa e o templo. In: O Estado de São Paulo, São Paulo, 26 jul 1914.

SEXTON, Randolph. American public buildings of today: city halls, court houses, municipal buildings, fire stations, libraries, museums, park and buildings. New York: Architectural Book Publishing, 1931.

. Spanish influence on architecture and decoration. New York, Brentano's, 1927.

SILVA, Joana Mello de Carvalho e. Nacionalismo e arquitetura em Ricardo Severo: Porto, 1869 - São Paulo, 1940. (Dissertação de mestrado). São Carlos: Escola de Engenharia de São Carlos, Universidade de São Paulo, 2005.

SMITH, Harvey P. Spanish traditions of San Antonio: a city with the same background as California. California: arts and architecture. Los Angeles: p. 34 - 36, Aug, 1930.

SMITH, Lieut. A manual of topographical drawing. New York: Willey \& Sons, 1902.

STURGIS, Russell. A dictionary of architecture and building: biographical, historical, and descriptive by and many architects, painters, engineers, and other expert writers, American and foreign. New York: MacMillan, 1901.

THE ARCHITECTURAL DIGEST: a pictorial digest of California's best architecture. Los Angeles: John Brasfield, 1920. 3v.

THE ARCHITECTURAL RECORD. Architectural Schools in the United States: University of Pennsylvania - n. 2. New York: v. 10, p.314-335, mar. 1901.

THE ASSAULT on the Mike: the success of big voices on the screen. California: arts and architecture. Los Angeles: p. 56 - 57, Feb, 1933.

THE CALIFORNIA tradition of hospitality inherited from the Don. California: arts and architecture. Los Angeles: p. 18, Feb, 1930.

THE CHARM of the early California days transplanted to modern California Life. California: arts and architecture. Los Angeles: p. 10, Jan, 1933. 
THE SÃO PAULO TRAMWAY, LIGHT \& POWER Co., LTD. Cinqüenta anos de progresso com São Paulo: 1900-1950. São Paulo, snt, 1950.

UMA RESIDENCIA á rua Pompeu Loureiro. Arquiteto Robert Prentice. Arquitetura $e$ Urbanismo. Rio de Janeiro: IAB, n.12, jan - fev, 1938, p. 16-21.

UMA RESIDENCIA confortável. Arquitetos Pires e Santos. Arquitetura e Urbanismo. Rio de Janeiro: IAB, mai - jun, 1939, p.499 - 501.

WOLFF, Silvia Ferreira Santos. Jardim América: o primeiro bairro-jardim de São Paulo e sua arquitetura. São Paulo: EDUSP / FAPESP / Imprensa Oficial, 2000.

ZAKIA, Silvia Amaral Palazzi. Mário Penteado: arquiteto e obra. (Dissertação de mestrado). Campinas: Mestrado em Urbanismo, Centro de Ciências Exatas e de Tecnologia, Pontifícia Universidade Católica de Campinas, 2004. 